\title{
The observed diurnal cycle of low-level stratus clouds over southern West Africa: a case study
}

\author{
Karmen Babic $^{1}$, Bianca Adler ${ }^{1}$, Norbert Kalthoff ${ }^{1}$, Hendrik Andersen $^{1}$, Cheikh Dione ${ }^{2}$, Fabienne Lohou ${ }^{2}$, \\ Marie Lothon ${ }^{2}$, and Xabier Pedruzo-Bagazgoitia ${ }^{3}$ \\ ${ }^{1}$ Institute of Meteorology and Climate Research, Karlsruhe Institute of Technology (KIT), Karlsruhe, Germany \\ ${ }^{2}$ Laboratoire d'Aérologie, Université de Toulouse, CNRS, UPS, Toulouse, France \\ ${ }^{3}$ Meterology and Air Quality Group, Wageningen University and Research, Wageningen, the Netherlands
}

Correspondence: Karmen Babić (karmen.babic@kit.edu)

Received: 27 July 2018 - Discussion started: 13 August 2018

Revised: 14 November 2018 - Accepted: 23 January 2019 - Published: 31 January 2019

\begin{abstract}
This study presents the first detailed observational analysis of the complete diurnal cycle of stratiform low-level clouds (LLC) and involved atmospheric processes over southern West Africa (SWA). The data used here were collected during the comprehensive DACCIWA (Dynamics-Aerosol-Chemistry-Cloud-Interactions in West Africa) ground-based campaign, which aimed at monitoring LLC characteristics and capturing the wide range of atmospheric conditions related to the West African monsoon flow. In this study, in situ and remote sensing measurements from the supersite near Savè (Benin) collected during a typical day, which is characterized by the onset of a nocturnal lowlevel jet (NLLJ) and the formation of LLC, are analyzed. The associated dynamic and thermodynamic conditions allow the identification of five different phases related to the LLC diurnal cycle: the stable, jet, stratus I, stratus II, and convective phases. The analysis of relative humidity tendency shows that cooling is a dominant process for LLC formation, which leads to a continuous increase in relative humidity at a maximum rate of $6 \% \mathrm{~h}^{-1}$, until finally saturation is reached and LLC form with a cloud-base height near the height of NLLJ maximum. Results of heat budget analysis illustrate that horizontal cold-air advection, related to the maritime inflow, which brings the cool maritime air mass and a prominent NLLJ wind profile, has the dominant role in the observed strong cooling of $-1.2 \mathrm{~K} \mathrm{~h}^{-1}$ during the jet phase. The contribution from horizontal cold advection is quantified to be up to $68 \%$, while radiative cooling and sensible heat flux divergence both contribute $16 \%$ to the observed heat budget below the NLLJ maximum. After the LLC form (stratus phases
\end{abstract}

I and II), turbulent mixing is an important factor leading to the cooling below the cloud base, while strong radiative cooling at the cloud top helps to maintain thick stratus.

\section{Introduction}

During the summer monsoon season in southern West Africa (SWA), stratiform low-level clouds (LLC) frequently form during the night with a typical cloud-base height $(\mathrm{CBH})$ of several hundred meters above ground, and cover extensive areas (Knippertz et al., 2011; Schrage and Fink, 2012; Schuster et al., 2013; van der Linden et al., 2015). Using multiyear (2006-2011) surface synoptic observations and various satellite products, van der Linden et al. (2015) presented a first climatology of the LLC during the wet monsoon season (July-September) in SWA. They found that shortly after sunset LLC frequently form along the coast of Guinea and spread farther inland in the course of the night, while LLC are most frequent upstream of elevated terrain. The LLC reach a maximum northward extent between 09:00 and 10:00 UTC, with the maximum aerial coverage of approximately $800000 \mathrm{~km}^{2}$. Similar results were obtained by Schrage and Fink (2012) and Schuster et al. (2013), who analyzed the data collected during the African Monsoon Multidisciplinary Analysis (AMMA) 2006 special observing periods (May-October). Due to their persistence until the early afternoon hours, LLC significantly influence the radiation budget at the surface (Schuster et al., 2013; Hill et al., 2018), 
and thus affect the diurnal cycle of the atmospheric boundary layer (ABL) and regional climate (Knippertz et al., 2011).

So far, only few studies focused on the analysis of mechanisms and factors controlling the onset and maintenance of LLC in SWA. Schrage and Fink (2012) used remote sensing observations at Nangatchori in central Benin, Schuster et al. (2013) performed regional simulations for the whole 2006 monsoon season using the Weather Research and Forecasting (WRF) model, while Adler et al. (2017) performed highresolution numerical simulations with the Consortium for Small-Scale Modeling (COSMO) model for a case study and an area around the city of Savè (Benin). Schrage and Fink (2012) found the formation of LLC to be related to the onset of the nocturnal low-level jet (NLLJ) and the same conclusion is obtained from the model simulations. Schrage and Fink (2012) proposed the strong wind shear underneath the NLLJ, which leads to the destabilization of the near-surface layer and increased turbulent upward mixing of cold air and moisture, to be the major process for the cloud formation at Nangatchori. On the other hand, modeling results of Schuster et al. (2013) suggest that turbulent processes related to the NLLJ are more dominant close to the coast, while orographically forced lifting on the windward side of mountains is more important farther inland. The importance of horizontal cold-air advection with the southwesterly monsoon flow for the formation of LLC was found by both modeling studies (Schuster et al., 2013; Adler et al., 2017). Finally, after LLC form, radiative cooling at the cloud top, as well as the vertical mixing below the cloud, help to maintain the stratus deck. High-resolution simulations suggest that additional processes could be important for LLC formation, such as vertical cold-air advection, which is related to orographically induced lifting as well as to gravity waves, and enhanced convergence and upward motion upstream of existing clouds (Adler et al., 2017).

While LLC and involved phenomena are the integral part of the West African Monsoon system, climate models struggle to realistically represent them. Knippertz et al. (2011) conducted a comprehensive analysis of global climate models and found positive biases in NLLJ speed, negative biases in LLC cover, and consequently large overestimation of solar radiation (of up to $90 \mathrm{~W} \mathrm{~m}^{-2}$ ). Hannak et al. (2017) extended the analysis of Knippertz et al. (2011) to the latest global climate model data sets. While similar biases are found as in Knippertz et al. (2011), the authors have identified differences in subgrid cloud schemes as one of the possible reasons why models struggle to realistically represent LLC.

Up to now, spatial and temporal investigations of LLC in this region have been performed based mainly on satellite images, synoptic observations and few modeling studies mentioned above, while high-quality observational data sets were rare. Due to these limitations, processes that control the formation and dissolution of LLC are still not fully understood. Moreover, understanding of these processes has important practical implications, such as improving operational fore- cast and predictions of the West African monsoon in weather, seasonal and decadal climate simulations (Knippertz et al., 2011; Hannak et al., 2017). In order to fulfill this gap, a comprehensive field campaign was conducted within the framework of the Dynamics-aerosol-chemistry-cloud-interactions over West Africa (DACCIWA) project (Knippertz et al., 2015) in June and July 2016. The campaign included groundbased measurements at three supersites in Ghana, Benin, and Nigeria (Kalthoff et al., 2018), radiosonde and aircraft measurements (Flamant et al., 2018). Knippertz et al. (2017) presented the large-scale setting and synoptic and mesoscale weather systems, which affected the region during the DACCIWA campaign, identifying different phases of similar meteorological conditions, while Kalthoff et al. (2018) gave an overview of the diurnal cycle of the ABL conditions as well as of the conditions related to nocturnal LLC at three groundbased supersites.

This study is conducted in concert with the analyses presented by Adler et al. (2019) and Dione et al. (2018). In this study we focus on the description of the diurnal cycle of LLC and identification of physical processes and factors that control the formation, maintenance, and dissolution of LLC during one typical night with undisturbed monsoon conditions and persistent LLC (e.g., Flamant et al., 2018; Kalthoff et al., 2018). For this we use measurements performed at the Savè supersite during intensive observation period (IOP) 8 (7-8 July 2016). Specifically, we aim at identifying the main factors leading to the relative humidity $(\mathrm{RH})$ change and LLC formation and assessing the heat budget terms for different phases during the life cycle of the LLC. Although we show only one case study, the dominant processes are considered to be representative of a major part of the DACCIWA campaign, especially for the post-onset phase of monsoon (22 June20 July 2016, Knippertz et al., 2017). This is supported by the analysis of Adler et al. (2019), who perform in a consistent manner an analysis for 11 IOPs, and we find a good agreement between these two studies. Additionally, Adler et al. (2019) investigate LLC characteristics (vertical extent, coverage, onset time, and horizontal distribution and evolution), as well as the intra-night variability of boundary-layer conditions and processes relevant for LLC formation. Dione et al. (2018) present a detailed statistical analysis of the characteristics of the LLC and the dynamics in the lower atmosphere for a 41-day period.

This paper is organized as follows: in Sect. 2 a brief description of the study site, data, and methods used is given. In Sect. 3, the evolution of LLC is described, followed by the presentation of atmospheric dynamic and thermodynamic conditions in Sect. 4. In this section we also analyze the RH tendency and the heat budget. The discussion of results is presented in Sect. 5, while the main findings are summarized in Sect. 6. 


\section{Data and methods}

\subsection{Meteorological measurements at the Savè supersite}

In this study we analyze the data collected during the DACCIWA ground-based measurement campaign, which took place between 14 June and 31 July 2016 at the Savè (Benin) supersite (Fig. 1). The comprehensive and unique data set of the ground-based campaign consists of remote sensing and in situ data (Bessardon et al., 2019), which enable the investigation of cloud characteristics and dynamic and thermodynamic conditions at high temporal and vertical resolutions (Kalthoff et al., 2018). During the campaign, 15 IOPs were conducted, during which, in addition to normal radiosondes launched at standard synoptic times, frequent radiosondes were launched at regular intervals in between the normal radiosondes. The Savè supersite $\left(8.00^{\circ} \mathrm{N}, 2.43^{\circ} \mathrm{E} ; 166 \mathrm{~m}\right.$ above sea level (a.s.1.)) is located approximately $185 \mathrm{~km}$ inland from the coast in a moderately hilly region which is favorable for LLC formation (van der Linden et al., 2015; Adler et al., 2017; Kalthoff et al., 2018). The vegetation cover at the site is characterized by grass and bushes (waist deep). A comprehensive measurement setup at this supersite allows the detailed investigation of atmospheric conditions and identification of atmospheric processes relevant to the observed life cycle of LLC. Meteorological data used here comprise near-surface meteorological parameters, 30 min averaged turbulence fluxes and turbulence variables, which were calculated using the TK3.11 software (Mauder et al., 2013), and radiation fluxes (Kohler et al., 2016).

The dynamic and thermodynamic conditions in the ABL were measured with radiosondes (normal and frequent) and different continuously running active and passive remote sensing instruments (Derrien et al., 2016; Handwerker et al., 2016; Wieser et al., 2016). The radiosondes were launched in regular intervals of $1.5 \mathrm{~h}$, starting at 17:00 UTC prior to the IOP day (7 July) until 11:00 UTC on the IOP day. For Benin, local standard time equals UTC plus $1 \mathrm{~h}$. Additionally, the radiosounding measurements at the coastal station Accra (Ghana, Fig. 1) were performed as part of the DACCIWA radiosonde campaign (Flamant et al., 2018). Highresolution information of flow conditions (wind speed and direction) is obtained from a sodar (for lower part of the ABL) and an ultra-high frequency (UHF) wind profiler (above 200 m a.g.l.) measurements. Additionally, Doppler lidar azimuth scans at $15^{\circ}$ elevation angle (plan-position indicator, PPI) provided the information on the three-dimensional radial velocity field by applying the velocity-azimuth display (VAD; Browning and Wexler, 1968) technique. In addition to the retrieval of the mean horizontal wind field with the VAD method, PPI scans can be used to quantify turbulence (e.g., Bonin et al., 2017). We use PPI scans performed at a $15^{\circ}$ elevation angle to estimate the variance of radial velocity for each range ring and project them to the vertical axis. The procedure is as follows: first we dismiss all range rings affected by clouds and remove outliers and echos by hard targets. Then we estimate the mean wind speed and direction using a simplified version of the VAD method (Bonin et al., 2017). The variance for each range ring is calculated by averaging the deviation from the fitted curve and corrected for uncorrelated noise. We obtained the information on liquid water path (LWP) and integrated water vapor (IWV) from the microwave radiometer (Wieser et al., 2016) using the retrieval algorithm provided by the University of Cologne (Löhnert and Crewell, 2003; Löhnert et al., 2009). This algorithm was trained on a set of more than 12000 radiosonde profiles measured between 1980 and 2014 in Abidjan (Ivory Coast). These quantities are needed for the radiative transfer model, which we used to obtain vertical profiles of radiative fluxes, and which is described in Sect. 2.3.

\subsection{Measurements of LLC characteristics}

The cloud characteristics are documented by ceilometer $(\mathrm{CBH})$, cloud radar measurements (cloud top height, $\mathrm{CTH}$ ), and infrared (IR) cloud camera (cloud cover). The CHM15k ceilometer operates at a wavelength of $1064 \mathrm{~nm}$ and a pulse rate of 5-7 kHz. It records the backscatter every $60 \mathrm{~s}$ up to $15 \mathrm{~km}$ a.g.l. and has a vertical resolution of $15 \mathrm{~m}$. A $35.5 \mathrm{GHz}$ cloud radar was operated in the vertical stare mode to provide radial velocity and reflectivity profiles from $150 \mathrm{~m}$ to $15 \mathrm{~km}$ a.g.l. at a vertical resolution of $30 \mathrm{~m}$ and a temporal resolution of $10 \mathrm{~s}$. The $\mathrm{CBH}$ is determined from the attenuated backscatter coefficient profiles based on a threshold method (manufacturer Lufft, personal communication, 2016), while the CTH is derived from the measurements of radar reflectivity of hydrometeors using a threshold of $-35 \mathrm{dBz}$; i.e., reflectivities larger than $-35 \mathrm{dBz}$ are considered clouds (Bauer-Pfundstein and Goersdorf, 2007). In addition to this, information on sky conditions is obtained with the IR cloud camera. This camera takes images of the fraction of sky every $2 \mathrm{~min}$ with an opening angle of $43^{\circ} \times$ $32^{\circ}$ (i.e., $166 \mathrm{~m} \times 114 \mathrm{~m}$ covered area at $200 \mathrm{~m}$ height) and a wavelength range of 7.5-13.5 $\mu \mathrm{m}$. The sky images are coded in three colors: red, green, and blue (RGB). The color of the image depends on the emissivity of the sky and, consequently, on the temperature. Thus, a red image indicates a relatively warm temperature, while blue indicates colder temperatures. Based on this, it is possible to distinguish cloudfree periods, periods with continuous cloud deck, as well as periods with intermittent (stratus fractus) clouds.

The Spinning Enhanced Visible Infra-Red Imager (SEVIRI) data provided the spatiotemporal characteristics of LLC in the larger area. The spatiotemporal distribution and evolution of LLC in the study area is observed with the SEVIRI (Schmetz et al., 2002) sensor, mounted on the geostationary Meteosat Second Generation satellite system. Information on LLC coverage is inferred using three channels: the visible at $0.6 \mu \mathrm{m}$ (VIS), middle-infrared at $3.9 \mu \mathrm{m}$ (MIR) and thermal-infrared at $10.8 \mu \mathrm{m}$ (TIR) at their native reso- 


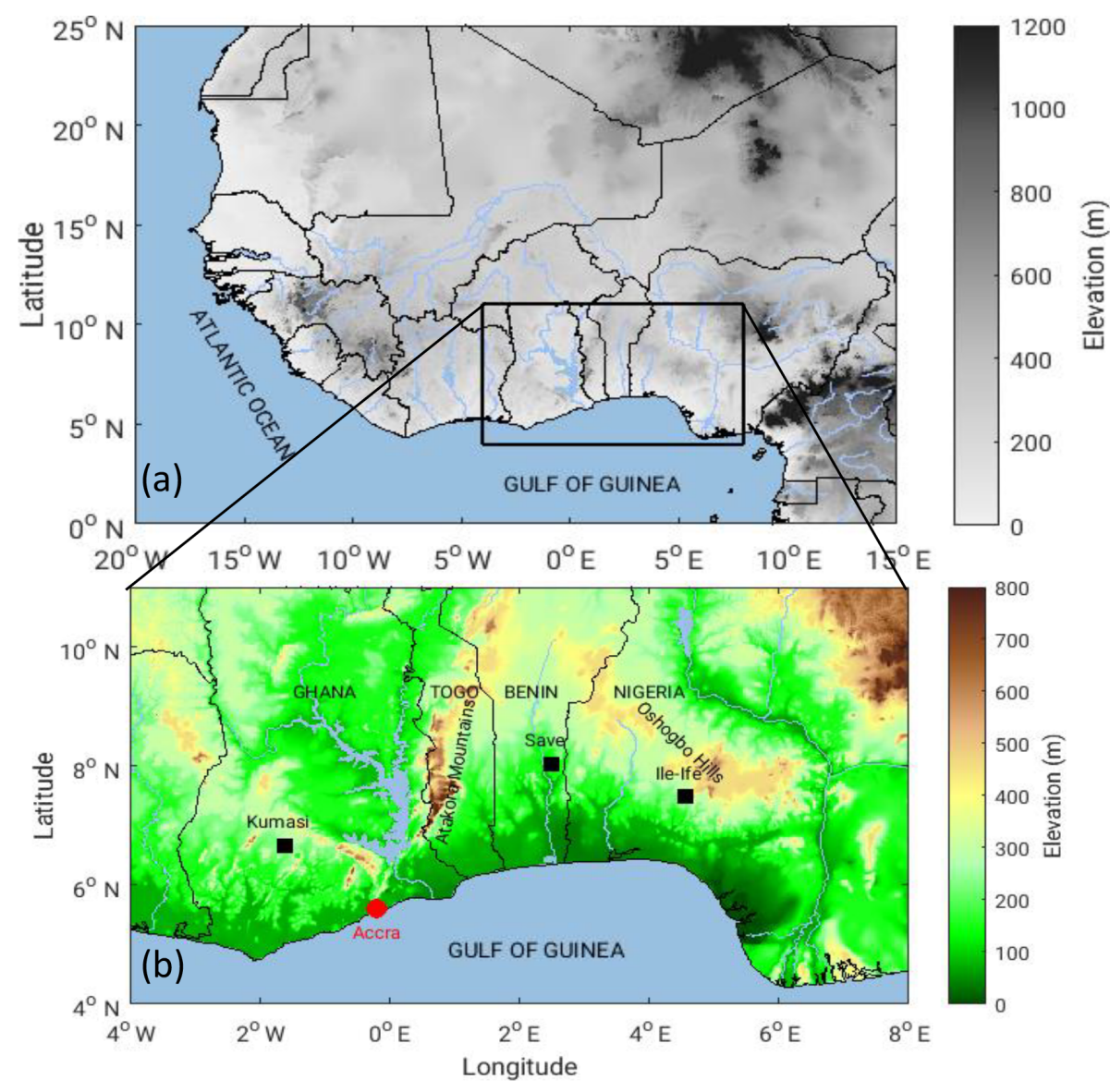

Figure 1. (a) The black rectangle indicates the geographical location of the DACCIWA area of interest. (b) Topographic map of the investigation area. The three supersites, including the Savè supersite, are indicated with black squares. The Accra coastal radiosonde station is shown with a red circle.

lution of $3 \times 3 \mathrm{~km}^{2}$ (at nadir) and a repeat rate of $15 \mathrm{~min}$. At night, LLC are illustrated using the brightness temperature difference of the TIR and the MIR channels, which is a proxy for cloud droplet size and can thus be used to detect low clouds (smaller droplets) (Hunt, 1973). The underlying concept is based on the assumption that the average droplet size within the LLC is smaller than in higher-altitude clouds. As the emissivity difference of the TIR and the MIR is dependent on cloud droplet size (Hunt, 1973), the brightness temperature difference between TIR and MIR has been used frequently to detect low clouds from various satellite platforms (e.g., Eyre et al., 1984; Cermak and Bendix, 2007). However, during daytime, the channel at $3.9 \mu \mathrm{m}$ measures a mixture of outgoing thermal and reflected solar radiation, so this method does not work after sunrise (Cermak and Bendix, 2008). Therefore, the reflectance in the VIS channel is used to illustrate cloud coverage during daytime. In order to easily distinguish between these two techniques, different colormaps in Fig. 2 are chosen for the different techniques. For both, daytime and nighttime, higher-level clouds are masked out by applying a TIR brightness temperature threshold at
$283 \mathrm{~K}$. Based on observed temperature profiles, this approximates a cloud-top altitude of $2.7 \mathrm{~km}$. It should be noted that edges of mid-level clouds might be missed by the TIR filter. The satellite imagery shown in this study is meant to be a purely qualitative representation of LLC occurrence and distribution during the IOP.

\subsection{SBDART radiative transfer model}

Vertical profiles of radiative fluxes are computed with the Santa Barbara DISORT Atmospheric Radiative Transfer (SBDART) model. SBDART is a software tool which computes plane-parallel radiative transfer in clear and cloudy conditions within the Earth's atmosphere (Ricchiazzi et al., 1998). Thanks to the rich data set obtained within the field campaign, many of the input parameters can be specified, allowing for a realistic modeling of radiative fluxes. For example, based on the radiosonde measurements, vertical profiles of pressure, temperature, and water vapor are used in the model, while the microwave radiometer provides IWV values. The standard tropical ozone density profile is used as input (linearly interpolated to model levels), since this infor- 

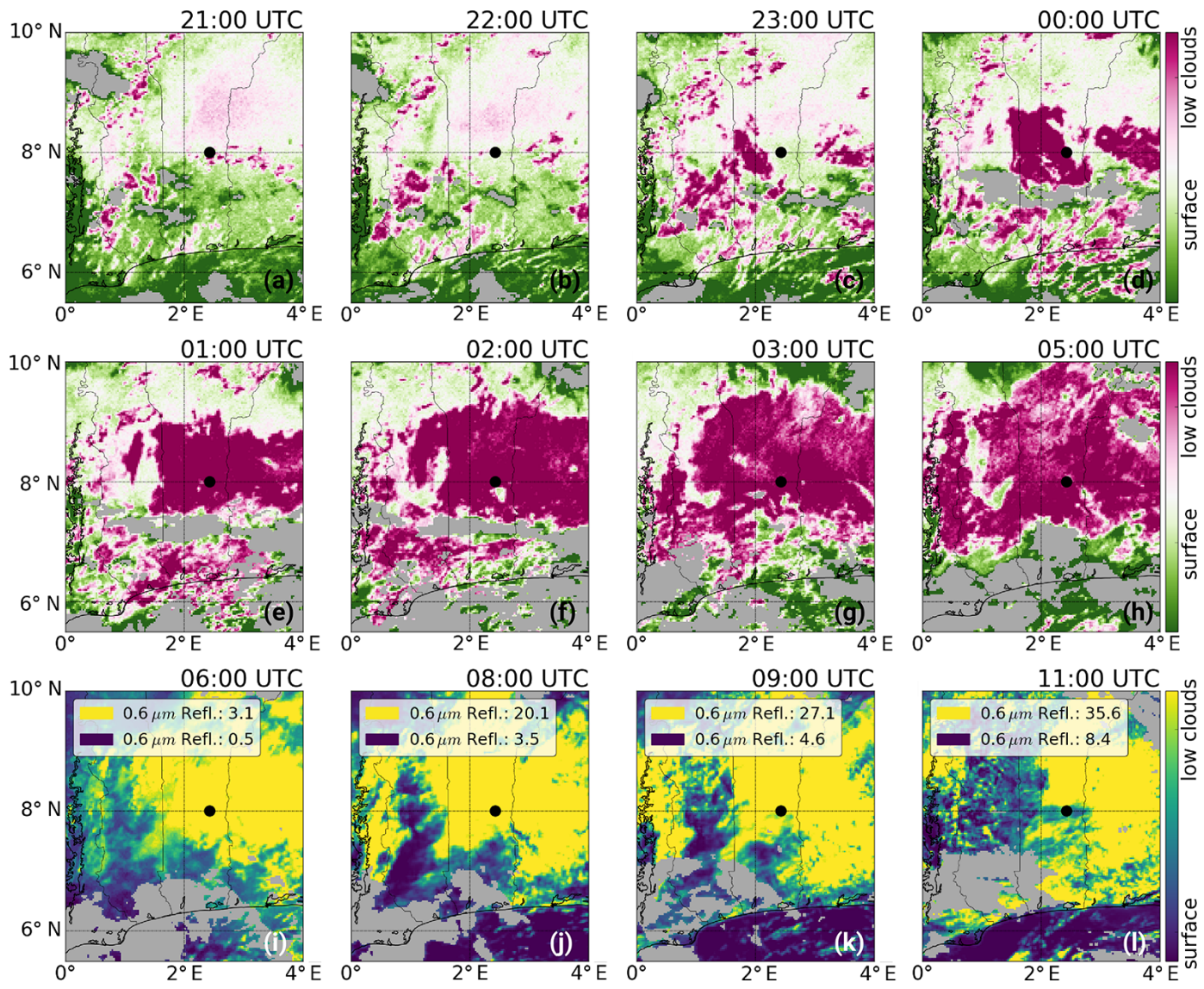

Figure 2. The difference in brightness temperature for spectral channels 10.8 (TIR) and $3.9 \mu \mathrm{m}$ (MIR) is shown in panels (a)-(h) for the nighttime period. The range of the color bar for the nighttime period (a-h) is between -1 and $3.5 \mathrm{~K}$. Purple color indicates LLC. Time is indicated in the top right corner in each panel, with panel (a) showing 21:00 UTC on 7 July 2016 and (l) showing 11:00 UTC on 8 July 2016. For the daytime period (i-l) the reflectance in the visible channel $(0.6 \mu \mathrm{m})$ is shown and the range of the color bar is indicated in the legend. The gray areas indicate the TIR brightness temperature threshold at $283 \mathrm{~K}$, which indicates higher-level clouds. The Savè supersite is indicated with a black circle.

mation is not available from measurements. In total, 65 vertical input levels are specified, with $50 \mathrm{~m}$ resolution in the lowest 2.5 and $1 \mathrm{~km}$ resolution between 3 and $16 \mathrm{~km}$.

The spectral range of radiative flux calculations is selected to correspond to the measurement range of the near-surface solar radiation instrument, namely between 0.34 and $2.2 \mu \mathrm{m}$ in the shortwave range and $4.5-42 \mu \mathrm{m}$ in the longwave range with spectral resolutions of 0.01 and $0.1 \mu \mathrm{m}$, respectively. The solar illumination angles are computed from the specified day of year, time, and geographic coordinates. A spectrally uniform albedo equal to 0.2 (Kalthoff et al., 2018) is set for the surface reflectance properties. The boundary-layer aerosol type is set to typical rural, while the vertical optical depth of the boundary-layer aerosol is defined as a mean daily aerosol optical depth measured on 7 July (Level 1.5, http://aeronet.gsfc.nasa.gov/, last access: 15 March 2018) and is equal to 0.36 . In the case of cloud presence, cloud properties, such as cloud-layer range and the optical thickness of the cloud layer, are specified. The cloud optical thick- ness is determined from the LWP measurements and the cloud droplet effective radius. We use the default value of cloud droplet effective radius of $8 \mu \mathrm{m}$ as this value is within the range of aircraft measurements in the area (Deetz et al., 2018b; Taylor et al., 2019). The phase function model used in cloud layers is Mie scattering. All other input parameters correspond to the default ones. Sensitivity tests were also performed in order to inspect how sensitive the model output is to input parameters, and the configuration which gave the best agreement of net longwave and shortwave radiation with the near-surface observations was chosen.

\section{Characteristics of the diurnal cycle of LLC}

The SEVIRI-based information about the spatial distribution and temporal evolution of LLC is shown in Fig. 2. In the early evening, some patchy LLC are present in the investigation area and are confined to higher terrain (Fig. 1) of the Atakora Mountains range (Togo) and upstream of the Os- 
hogbo Hills (Nigeria) (Fig. 2a, b). After 22:00 UTC, the first LLC formed southwest, i.e., upstream, of Savè and then extended to the downstream side by 00:00 UTC (Fig. 2c, d). At the same time, the area in the neighboring Nigeria covered with LLC was extending westwards until the two areas merged into one large area around 01:00 UTC (Fig. 2d, e). At about 02:00 UTC, LLC have already extended and cover a substantial part of the domain (Fig. 2f), which continues to grow in the course of the night (Fig. 2g), so that at 05:00 UTC LLC cover the large part of the investigation area (Fig. 2h). After sunrise at around 06:00 UTC (Fig. 2i), LLC start slowly to dissipate (Fig. 2j, k); however, at 11:00 UTC (Fig. 2l) their presence in the domain is still substantial.

The ceilometer backscatter measurements at Savè (Fig. 3a) show some low- and mid-level clouds (up to $3 \mathrm{~km}$, not shown) present between 18:00 and 22:00 UTC, followed by a cloud-free period. The LLC formed around midnight, with $\mathrm{CBH}$ at around $300 \mathrm{~m}$ a.g.l., and the same was observed by SEVIRI (Fig. 2d). These LLC are maintained during the rest of the night and even after sunrise, with $\mathrm{CBH}$ at approximately $250 \mathrm{~m}$ a.g.l. After around 08:00 UTC, the CBH rises approximately linearly with time. At first, the $\mathrm{CTH}$ is observed roughly at $500 \mathrm{~m}$ a.g.l., indicating on average a $250 \mathrm{~m}$ deep cloud layer, with a period between 01:00 and 03:00 UTC without a clear cloud radar signal, therefore making it difficult to determine the CTH for the whole period (Fig. 3b). After 03:00 UTC, LLC are persistent until 08:00 UTC, with the CTH roughly constant at $650 \mathrm{~m}$ a.g.l. forming a $400 \mathrm{~m}$ deep cloud layer. After around 08:00 UTC, the CTH rises linearly as well. The microwave radiometer measurements of the LWP reveal varying cloud characteristics during the night (Fig. 3c). In the first couple of hours LLC contain less liquid water, most likely due to the combination of a shallow cloud layer and lower optical thickness, and according to the sky conditions obtained with an IR cloud camera, they are intermittent as well (Fig. 3d). After about 03:00 UTC, the LWP increases considerably probably because the cloud deepens, while a continuous cloud cover is observed. A minimum of IWV is observed just prior to the LLC onset and in the course of the night only a slight increase is observed. The observed differences in LLC characteristics suggest varying atmospheric conditions; therefore, we inspect dynamic and thermodynamic conditions at Savè in the next section.

\section{Atmospheric conditions relevant for the diurnal cycle of LLC}

\subsection{Low-level jet and thermodynamic conditions}

We start the investigation of atmospheric conditions during this IOP by inspecting the horizontal wind field (Fig. 4). The large-scale conditions on this IOP are characterized by an about $1000 \mathrm{~m}$ deep monsoon layer with southwesterly winds and the African easterly jet above (Flamant et al., 2018). Note that on this particular IOP the observed monsoon depth is lower than for the whole DACCIWA investigation period, which has a median depth of $2 \mathrm{~km}$ (Dione et al., 2018). The minimum wind speed is found within the layer between about 1000 and $1500 \mathrm{~m}$ a.g.l., which corresponds to the transition layer between the southwesterly monsoon flow and easterlies above. In the African easterly jet layer, winds reach a maximum of $15 \mathrm{~m} \mathrm{~s}^{-1}$ at about $3500 \mathrm{~m}$ a.g.l. (see Fig. 4b in Dione et al., 2018). During the afternoon and early evening, a moderate northwesterly-to-southwesterly flow of $3 \mathrm{~m} \mathrm{~s}^{-1}$ prevails in the lowest $1500 \mathrm{~m}$ (Fig. 4a). The onset of NLLJ is observed at 20:30 UTC, with an abrupt increase in wind speed up to a maximum of $8 \mathrm{~m} \mathrm{~s}^{-1}$, at a height of $275 \mathrm{~m}$ a.g.l. At the time of the NLLJ onset wind direction changes from westerly to southerly and south-southwesterly. The height of the NLLJ maximum corresponds to the height at which LLC form roughly $3.5 \mathrm{~h}$ later (Fig. 3b). Once the clouds have formed, the NLLJ maximum shifts upwards to the height of around $450 \mathrm{~m}$ a.g.l., reaching the maximum speed of $10 \mathrm{~m} \mathrm{~s}^{-1}$ (Fig. 4a). A weakening of the NLLJ is seen after 04:00 UTC and the axis is lifted to around 600$700 \mathrm{~m}$ a.g.l. With respect to wind speed close to the surface, we observe a similar behavior to Lothon et al. (2008), with the wind speed only slightly increasing above $1.5 \mathrm{~m} \mathrm{~s}^{-1}$ after the NLLJ onset (Fig. 4b). The wind direction becomes less variable after the arrival of south-southwesterly NLLJ and southwesterly flow persists in the course of the night and the following morning.

The potential temperature isolines show that after the sunset at 18:00 UTC, a strong cooling of the layer close to the ground occurs, while coincident with the NLLJ onset this layer becomes deeper and reaches approximately $750 \mathrm{~m}$ depth (Fig. 4a). The period between the onset of NLLJ and the formation of LLC is characterized by the strongest decrease in temperature. After the continuous LLC deck has formed around 02:30 UTC, the temperature is roughly constant below the cloud base as well as within the cloud layer. The increase in the temperature coincides with the increase in the $\mathrm{CBH}$ after 08:00 UTC due to an evolving convective boundary layer (CBL).

So far we have seen that due to the observed varying atmospheric conditions, the investigated period can be divided into different phases. The first phase identified is the period between the sunset (18:00 UTC) and the onset of the NLLJ (20:30 UTC), when the increasing static stability causes the decoupling of the mixed layer from the stable surface layer, and this phase is denoted the stable phase. This phase is followed by the jet phase, a time period between the onset time of NLLJ and the formation of LLC (00:00 UTC), which marks the beginning of the stratus phase. The period of roughly $2.5 \mathrm{~h}$ after LLC formation is identified as stratus phase I, since inhomogeneous cloud cover and nonstationary atmospheric conditions are observed. This is followed by stratus phase II, which corresponds to the period 

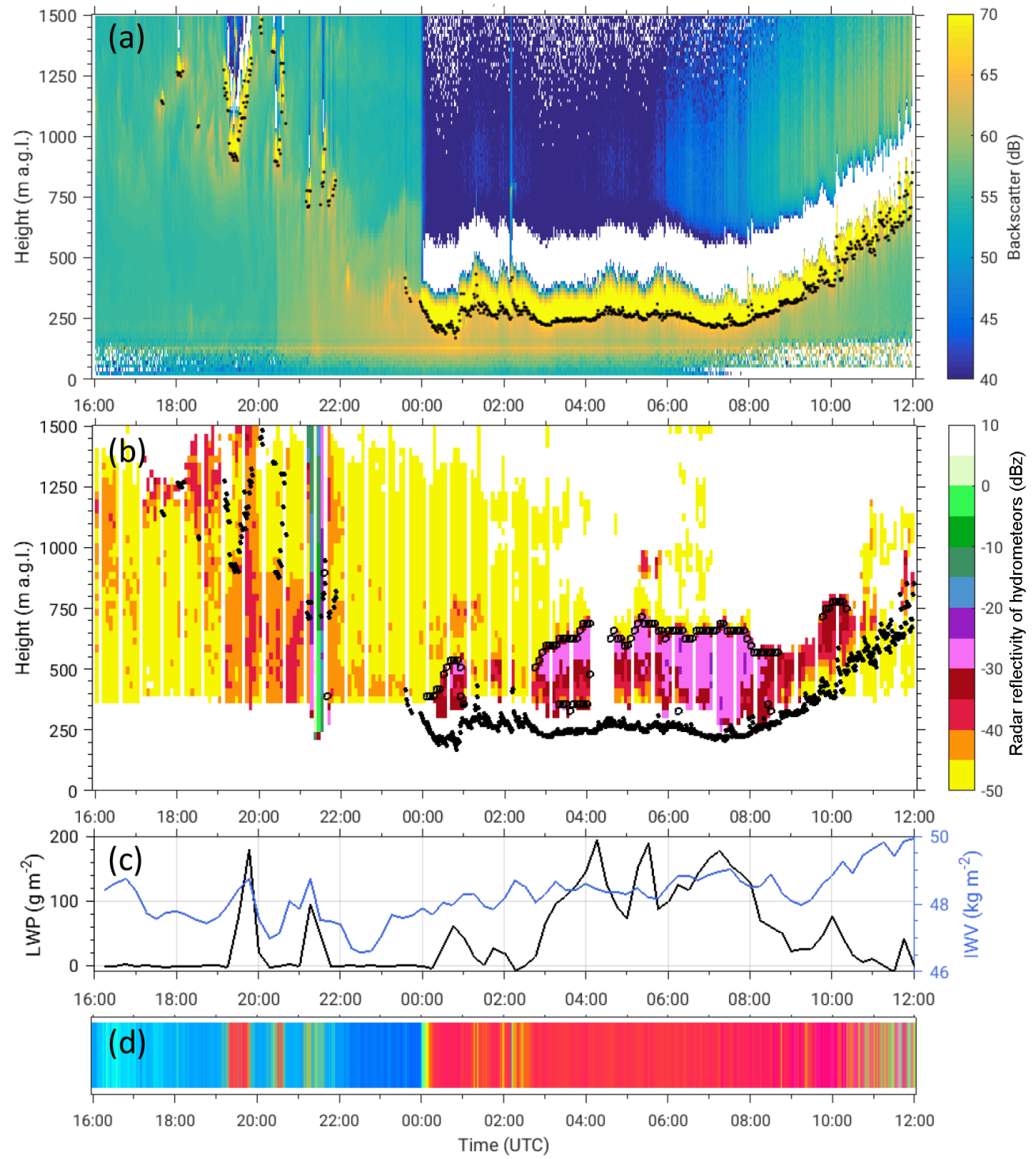

Figure 3. (a) Time series of ceilometer backscatter (color) and CBH (black dots) derived from the backscatter profiles. (b) The reflectivity of hydrometeors obtained by cloud radar (color), the CBH (black dots), and CTH (open circles) derived from the cloud radar using a threshold of $-35 \mathrm{dBz}$. (c) Time series of $30 \mathrm{~min}$ averaged LWP and IWV from microwave radiometer. (d) The RGB coded image of sky conditions obtained by IR cloud camera. The image shows relative contributions of red, green, and blue in a given pixel, where the color of the pixel depends on the emissivity of the sky area and its brightness temperature. The blue colors correspond to clear sky and the red color indicates LLC.

between 02:30 and 06:30 UTC, with a persistent LLC deck and quasi-stationary atmospheric conditions. The final convective phase is associated with growing $\mathrm{CBL}$ and is characterized by increased surface heating and lifting of the cloud base. Note that these five phases do not occur only on this particular IOP. Adler et al. (2019) found that the same phases can be distinguished for at least 10 other IOPs.

The wind shear underneath the NLLJ causes mechanical production of turbulence, which is considered to be an important process leading to the LLC formation (Zhu et al., 2001; Schrage and Fink, 2012; Schuster et al., 2013). Figure 5a shows the absolute values of the gradient Richardson number $(R i)$, which we calculate from radiosonde profile measurements for the $50 \mathrm{~m}$ averaged bins according to the following expression: $R i=\frac{g}{\theta} \frac{\partial \theta / \partial z}{\partial U / \partial z)^{2}}$, where $g$ is the acceleration due to gravity, $\theta$ is the potential temperature, and $U$ is the horizontal wind speed. Generally, turbulence is stronger as the Richardson number is smaller, while $R i=0.21-0.25$ is considered to be a critical Richardson number below which the flow is fully turbulent. When $R i$ is above 1 , the flow is considered to be laminar (e.g., Stull, 1988). Although two Doppler lidars were deployed at Savè, we could not obtain reliable 


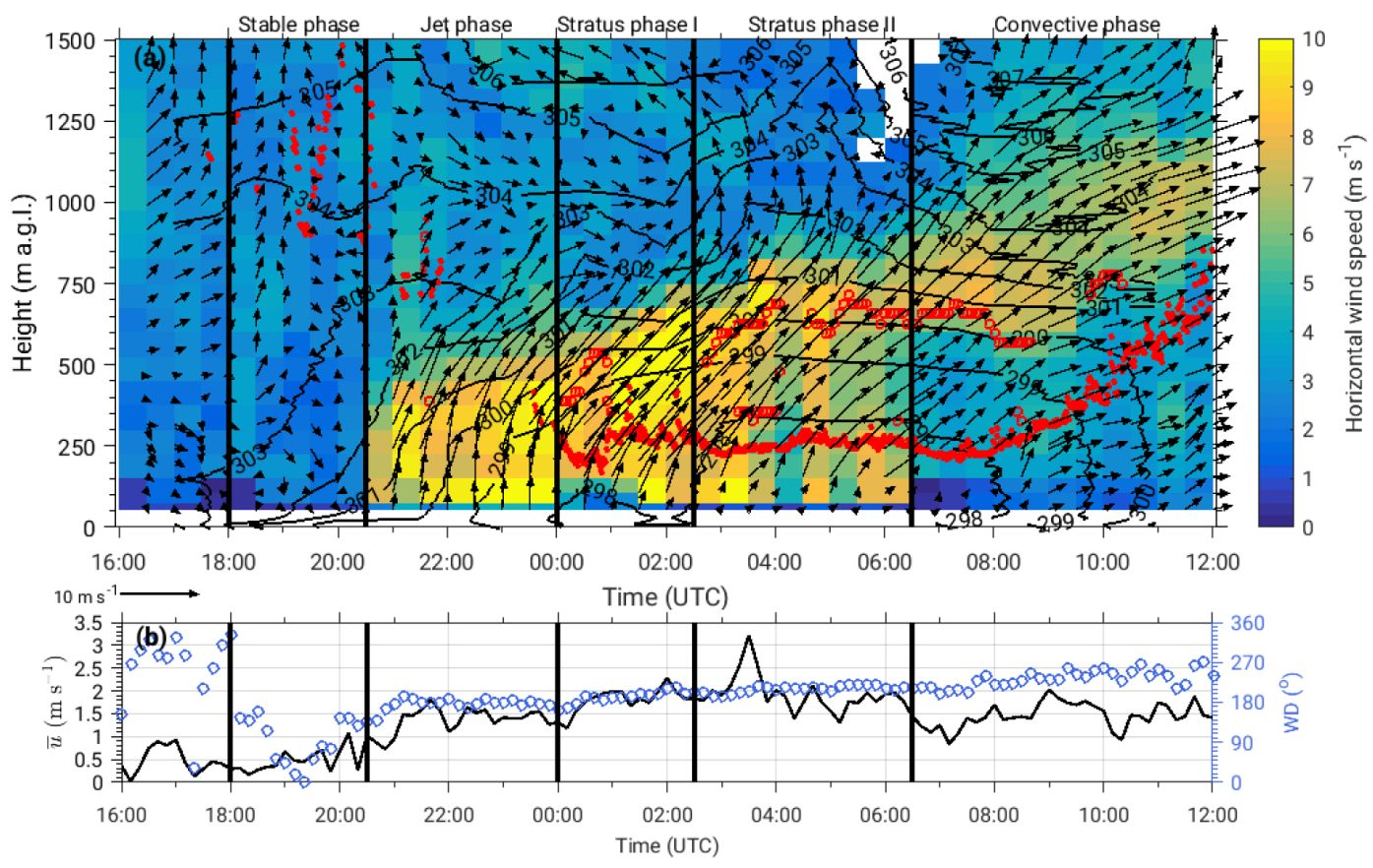

Figure 4. (a) Temporal evolution of the wind speed is shown in color, while arrows show wind direction obtained from sodar and UHF. Black contours show linearly interpolated potential temperature measured every $1.5 \mathrm{~h}$ by radiosondes. The red dots show $\mathrm{CBH}$ and $\mathrm{CTH}$ as shown with open red circles. (b) Time series of the near-surface 10 min averaged wind speed (black) and wind direction (blue) measured by energy balance station. The vertical black lines indicate the beginning of five different phases observed during this IOP.

measurements of vertical velocity fluctuations $\left(\sigma_{\mathrm{w}}\right)$ from the vertical stare mode observations (Adler et al., 2019). However, for an assessment of turbulence in the nocturnal cloudfree ABL, radial velocity measurements during PPI scans performed with the scanning Doppler lidar at Savè can be used too. The standard deviation of the radial velocity $\left(\sigma_{\mathrm{rv}}\right)$ measured by Doppler lidar is shown in Fig. $5 b$.

The importance of the NLLJ for LLC formation was first reported by Schrage and Fink (2012) for the SWA region, while Zhu et al. (2001) found similar importance for the nocturnal stratus in the Great Plains (USA). The signature of the NLLJ in the near-surface measurements is expected to be mostly seen in the TKE and not necessarily in the mean wind speed, as suggested by Lothon et al. (2008) in their AMMA study.

Figure $5 \mathrm{a}, \mathrm{b}$ show that before the sunset, a CBL is still present at 17:00 UTC, while during the stable phase turbulence decays due to the lack of mechanically generated mixing since the wind speed is rather low. Additionally, due to the longwave radiative cooling of the surface after sunset resulting in a negative sensible heat flux (Fig. 5d), the stable ABL develops and the negative buoyancy suppresses vertical mixing in the ABL, which is evident from low values of the TKE and a high stability parameter ( $\zeta$, Fig. 5c). The stability parameter is defined as the ratio of a height $z$ and the Obukhov length $L=-u_{*}^{3} /\left(k \frac{g}{\bar{\theta}} \overline{w^{\prime} \theta^{\prime}}\right)$, where $u_{*}$ is the friction velocity, $k=0.4$ is the von Kármán constant, and $\overline{w^{\prime} \theta^{\prime}}$ is the kinematic heat flux. This parameter is traditionally used as a measure of stability in the surface layer. Its magnitude is not directly related to static stability, but a positive sign indicates statically stable conditions, and a negative one implies unstable conditions (e.g., Stull, 1988). Simultaneously with the NLLJ onset, turbulence increases in the upper and lower shear zones of the jet. In the jet phase, below the NLLJ maximum and at the surface, static stability decreases, enabling stronger turbulent mixing and increase in TKE (Fig. 5a, c), while simultaneously the sensible heat flux decreases from $-10 \mathrm{~W} \mathrm{~m}^{-2}$ to its maximum value of $-16 \mathrm{~W} \mathrm{~m}^{-2}$ during the night (Fig. 5d). This enhanced vertical mixing is likely dominated by large coherent eddies (Sun et al., 2016) and leads to the vertical transport of cold air from the radiatively cooled surface. In the first couple of hours after the LLC formed, mostly intermittent turbulence $(0.25<R i<1)$ is present within the LLC in the shear zones of the upper part of the jet (Fig. 5a), while increased turbulent mixing is evident below the CBH (Fig. 5a, b), which results in a highly turbulent ABL. We notice that there is quite good agreement in the information about the turbulence intensity obtained from different measurement systems. The profiles of radial velocity variance show higher values in the lower and upper shear zones of the NLLJ maximum, as well as below the CBH.

Figure $6 \mathrm{a}, \mathrm{b}$ show temporal evolution of RH in combination with potential temperature and specific humidity. In the stable phase the increase in RH is confined to the lowest 


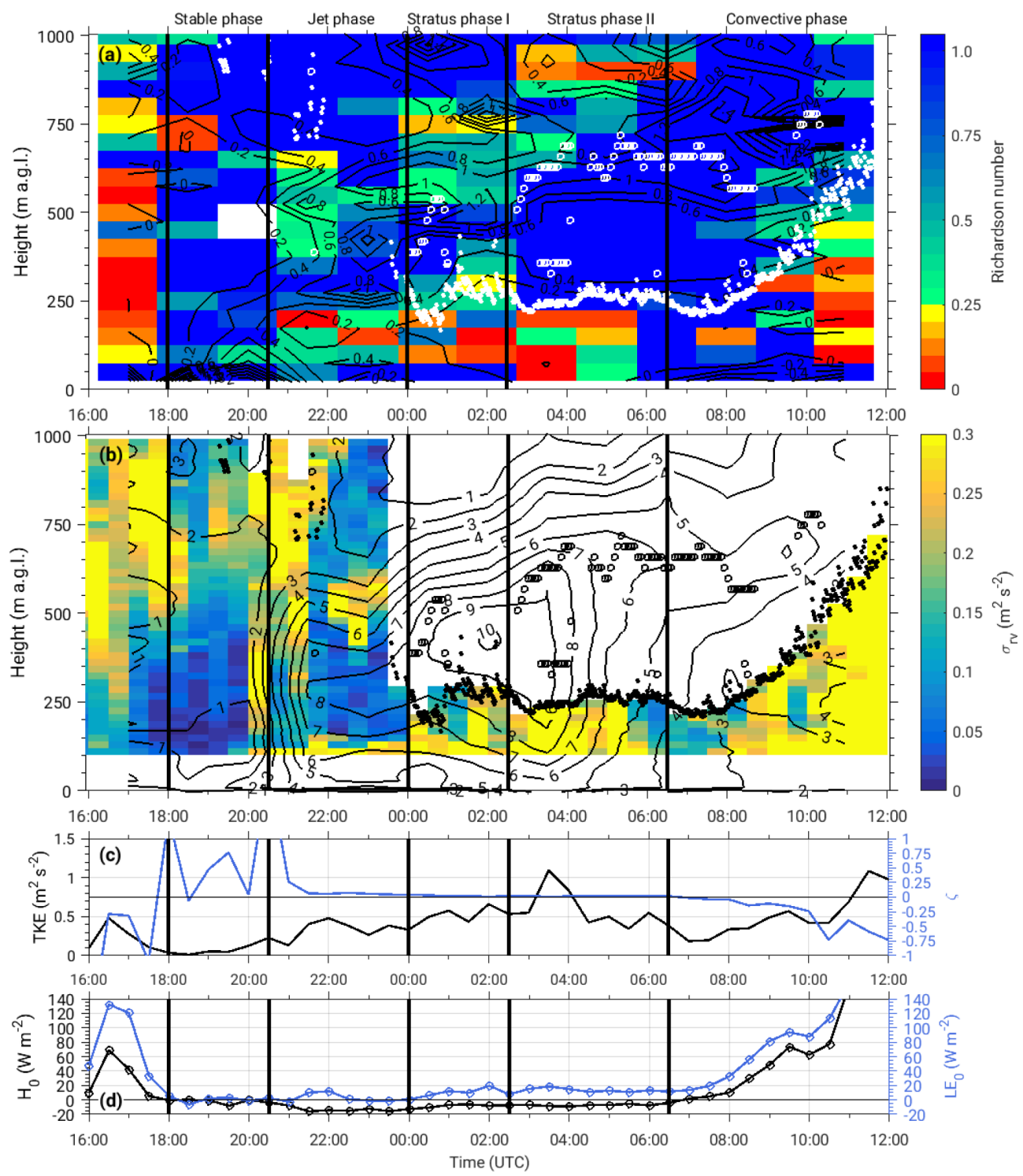

Figure 5. (a) The gradient Richardson number shown in color is calculated from radiosonde measurements. Black isolines show the vertical potential temperature gradient in $\mathrm{K}(100 \mathrm{~m})^{-1}$ calculated from radiosonde data. The white dots show CBH and open white circles denote CTH. (b) Variance of the radial velocity obtained by Doppler lidar measurements. The black contours show horizontal wind speed (in $\mathrm{m} \mathrm{s}^{-1}$ ) measured by radiosondes, while black dots show CBH and open black circles denote CTH. (c) Time series of the near-surface 30 min averaged TKE (black) and stability parameter $\left(\zeta\right.$, blue). (d) Time series of the near-surface sensible heat flux $\left(H_{0}\right.$, black) and latent heat flux $\left(\mathrm{LE}_{0}\right.$, blue) measured by the energy balance station. The vertical black lines indicate the beginning of five different phases observed during this IOP.

$100 \mathrm{~m}$, with the simultaneous decrease in temperature and increase in specific humidity. At the surface, temperature decreases by $4{ }^{\circ} \mathrm{C}$, while a small increase in specific humidity occurs $\left(\sim 1 \mathrm{~g} \mathrm{~kg}^{-1}\right)$, which finally leads to an increase in $\mathrm{RH}$ from $70 \%$ to $85 \%$ (Fig. 6c). We observe the drop in temperature by $3{ }^{\circ} \mathrm{C}$ in the period between 20:00 and 00:00 UTC, while simultaneously RH increases by $10 \%$ in the layer below $700 \mathrm{~m}$ a.g.l. We note that simultaneously with the RH increase after 20:00 UTC, an increase in ceilometer backscatter is observed as well (Fig. 3). This is most likely related to the aerosol hygroscopic growth, i.e., the size and composition of particle change due to their water vapor uptake (Deetz et al., 2018a; Haslett et al., 2018). At the beginning of the jet phase a slight increase in specific humidity $\left(\sim 0.7 \mathrm{~g} \mathrm{~kg}^{-1}\right.$ between 20:00 and 21:30 UTC) in the layer up to $1100 \mathrm{~m}$ a.g.l. is recorded. This increase in specific humidity occurs simultaneously with the increased turbulent mixing due to the NLLJ. In the second part of the jet phase (21:30-23:00 UTC), specific humidity decreased by $0.6 \mathrm{~g} \mathrm{~kg}^{-1}$ in the same layer. After saturation has been reached, LLC form. The unsteady 

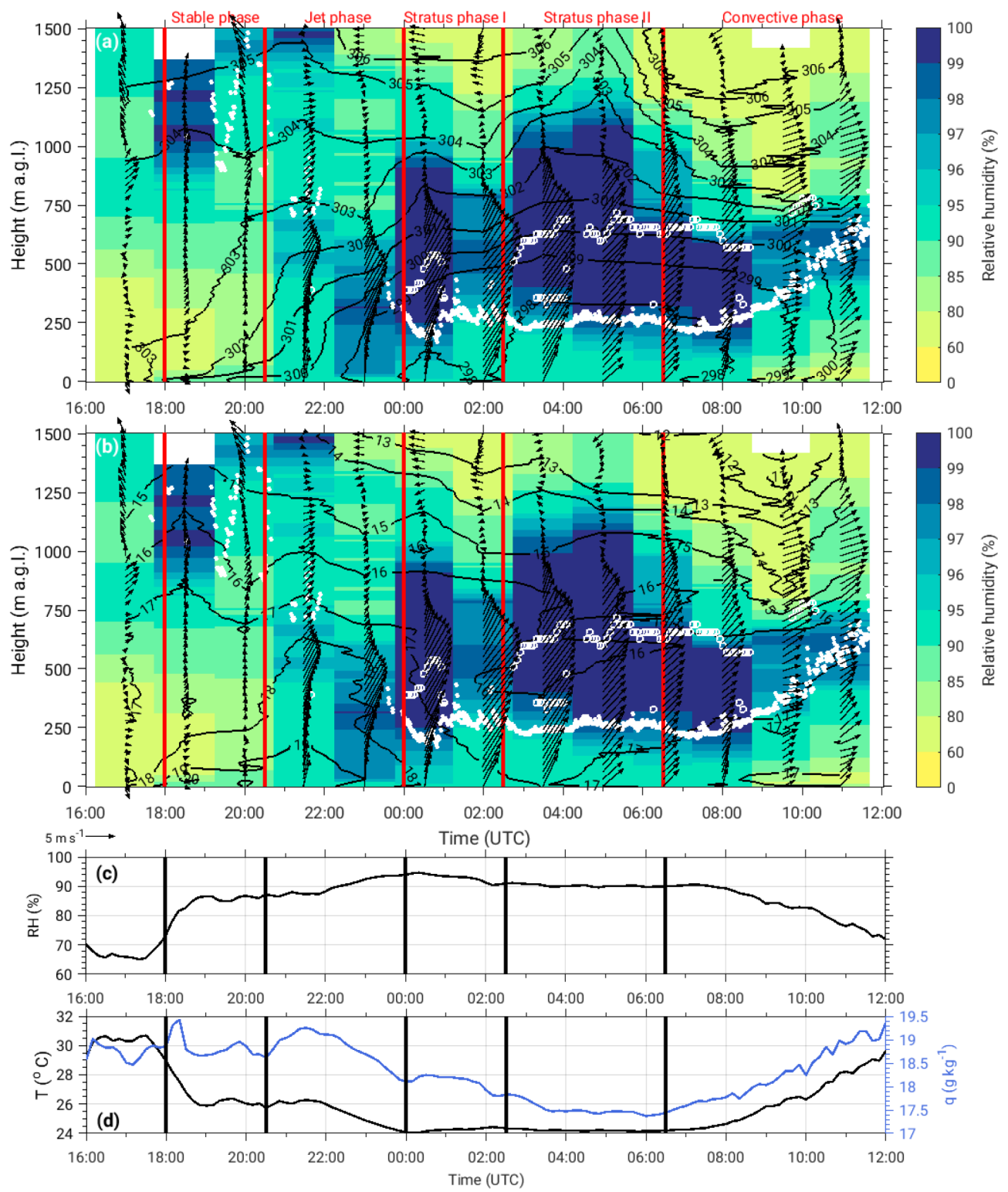

Figure 6. Temporal evolution of relative humidity (color) and potential temperature in Kelvin (panel a, isolines) and specific humidity in $\mathrm{g} \mathrm{kg}^{-1}$ (panel $\mathbf{b}$, isolines) in the lowest $1.5 \mathrm{~km}$ obtained from radiosonde profiles performed every $1.5 \mathrm{~h}$. The arrows show the horizontal wind vector from radiosondes. The $\mathrm{CBH}$ is indicated with white dots and the $\mathrm{CTH}$ with open white circles. Time series of 10 min averaged RH (c), temperature, and specific humidity (d) measured by the energy balance station $4 \mathrm{~m}$ a.g.l. The vertical red and black lines indicate the beginning of five different phases observed during this IOP.

conditions during the subsequent roughly 2 to $3 \mathrm{~h}$ (stratus phase I) are reflected in the RH measurements, with the sonde released at 02:00 UTC not reaching saturation. At the same time, the decrease in temperature is accompanied by the decrease in moisture; i.e., specific humidity decreased at a rate of $0.5 \mathrm{~g} \mathrm{~kg}^{-1} \mathrm{~h}^{-1}$ below $600 \mathrm{~m}$ a.g.1. This suggests that the air mass behind the NLLJ is drier than the environment at Savè. After 03:00 UTC, the conditions below the cloud base are quasi-stationary. The cooling of the near-surface layer weakens after the cloud deck forms, which leads to a near- neutrally stratified surface layer $(\zeta \approx 0$, Fig. $5 \mathrm{c})$ and contributes to further vertical mixing (Fig. 5c). After 08:00 UTC, $\mathrm{RH}$ starts to decrease with a simultaneous increase in temperature and specific humidity.

Based on radiosonde measurements, $\mathrm{CBH}$ and $\mathrm{CTH}$ can be determined by applying different criteria to RH measurements, such as the criteria described in Kalthoff et al. (2018). Their criteria detect cloud layers when $\mathrm{RH}$ is larger than $99 \%$. Comparison of $\mathrm{RH}$ profiles with $\mathrm{CBH}$ and $\mathrm{CTH}$ shown in Fig. 6a clearly shows that three radiosonde profiles would 
indicate a deeper cloud layer than detected by the cloud radar. While on average there is a good agreement between the $\mathrm{CBH}$ estimates from ceilometer and radiosondes, $\mathrm{RH}$ measurements can suggest a too high CTH due to the condensation on the sensor even after the sonde has risen above the cloud top. This issue highlights the advantage of the DACCIWA ground campaign and the multitude of instruments deployed allowing for the multiple estimates of certain parameters and their cross-validation.

In the following sections we present the analysis of processes relevant for the evolution of LLC and assess their relevance during different phases.

\subsection{Relative humidity tendency}

The observed changes in $\mathrm{RH}$ are a result of temperature $(T)$ and/or specific humidity $(q)$ changes, i.e., RH increases due to increase in specific humidity and/or decrease in temperature. In order to quantify whether the $q$ or $T$ change has a stronger influence on the RH tendency and consequently on LLC formation, we determine their respective contributions using consecutive radiosonde measurements. The terms of the $\mathrm{RH}$ tendency equation are derived from the time derivative of $\mathrm{RH}=e / e_{\mathrm{s}}$, where $e$ is the water vapor pressure and $e_{\mathrm{S}}$ is the saturation water vapor pressure. In the next step, we incorporate the Clausius-Clapeyron relation $\frac{\partial e_{\mathrm{s}}}{\partial T}=\frac{L_{\mathrm{v}} e_{\mathrm{s}}}{R_{\mathrm{v}} T^{2}}$ and the definition of water vapor pressure, $e=\frac{q}{0.378 q+0.622} p$, where $T$ is the air temperature in Kelvin, $p$ is the air pressure in $\mathrm{hPa}, L_{\mathrm{v}}$ is the latent heat of vaporization $\left(2.5 \times 10^{6} \mathrm{~J} \mathrm{~kg}^{-1}\right)$, and $R_{\mathrm{v}}=461.5 \mathrm{~J} \mathrm{~kg}^{-1} \mathrm{~K}^{-1}$ is the gas constant for water vapor. Finally, the contribution of absolute values and tendencies of $q$ and $T$ to RH tendency is calculated according to

$$
\begin{gathered}
\underbrace{\frac{\partial \mathrm{RH}}{\partial t}}_{\text {(I) }}=\underbrace{\frac{p}{e_{\mathrm{s}}} \frac{0.622}{(0.378 q+0.622)^{2}} \frac{\partial q}{\partial t}}_{\text {(II) }} \\
\underbrace{-\frac{p}{e_{\mathrm{S}}} \frac{q L_{\mathrm{V}}}{(0.378 q+0.622) R_{\mathrm{v}} T^{2}} \frac{\partial T}{\partial t}}_{\text {(III) }} .
\end{gathered}
$$

Terms of Eq. (1) are calculated directly from available radiosonde measurements of $\mathrm{RH}, q, T$ and $p$. In Eq. (1), term (I) is the observed RH tendency, term (II) represents the contribution from $q$ change and term (III) from $T$ change. Term (III) includes the minus sign, which means that a positive value of this term indicates cooling and vice versa. For the calculation of RH, $q$ and $T$ tendencies we use soundings released at 18:30 and 20:00 UTC for the stable phase, at 20:00 and 23:00 UTC for the jet phase, at 23:00 and 03:30 UTC for the stable phase I, at 03:30 and 06:30 UTC for the stratus phase II and at 06:30 and 11:00 UTC for convective phase. Other quantities in Eq. (1) are calculated as averages of all soundings within each phase. The results are shown in Fig. 7. For each of the terms in Eq. (1) the range of uncertainty is determined by calculating uncertainty propa- gation from the known uncertainties of measurements, which are $\sigma_{T}=0.2{ }^{\circ} \mathrm{C}$ for $T$ and $\sigma_{\mathrm{RH}}=2 \%$ for $\mathrm{RH}$.

During the stable phase, $\mathrm{RH}$ increases in the layer below 300 ma.g.l., with a maximum of about $4 \% \mathrm{~h}^{-1}$ (Fig. 7a). Above this level up to roughly $700 \mathrm{~m}$ a.g.l., RH is almost constant, while above RH decreases. The decrease in the temperature is mostly responsible for the increase in $\mathrm{RH}$ below $300 \mathrm{~m}$, while on average there is a small positive moisture contribution. The median wind speed profile in this phase is less than $3 \mathrm{~m} \mathrm{~s}^{-1}$ in the lowest $1 \mathrm{~km}$. The large uncertainty for each of the terms in stable phase is due to the fact that the tendencies are calculated over a relatively short time period of just $1.5 \mathrm{~h}$. During the next phase, the layer with a significant increase in RH deepens to about $700 \mathrm{~m}$ a.g.l., with a maximum rate of $6 \% \mathrm{~h}^{-1}$ (Fig. 7b). The main bulk of this change is caused by cooling, while moisture change is negligible during the jet phase. The layer of the maximum change corresponds to the level of the NLLJ maximum. This is in agreement with results in Adler et al. (2019), who found that on average cooling is the main process leading to the increase in $\mathrm{RH}$ and saturation, while moistening contributes only little.

At the end of the jet phase the clouds form, but are intermittent during stratus phase I, which is characterized by almost constant RH within the cloud layer, while below the cloud base a small decrease in $\mathrm{RH}$ of $-1 \% \mathrm{~h}^{-1}$ is recorded (Fig. 7c). Although we still observe cooling in the lowest $1 \mathrm{~km}$ during this phase, the rate is much lower compared to the stable and jet phases. At the same time a competing, stronger negative contribution of the specific humidity change is observed. The median wind speed in the jet layer has even increased to $9 \mathrm{~m} \mathrm{~s}^{-1}$, with the NLLJ maximum shifting upwards to the cloud top. As the LLC deck grows and becomes thicker, the NLLJ maximum shifts further upward towards the cloud top during stratus phase II (Fig. 7d). As this phase lasts even after sunrise, the daytime heating causes the weakening of the jet wind speed, and we observe a stronger temperature increase above the CTH than below the $\mathrm{CBH}$. On average, a small positive RH tendency exists below the NLLJ maximum (about $0.5 \% \mathrm{~h}^{-1}$ ), mostly due to a positive $q$ tendency. In the convective phase, the temperature continues to increase below $700 \mathrm{~m}$ a.g.l., and has a stronger contribution to negative RH tendency, while the $q$ tendency is small (Fig. 7e). The analysis of RH tendency shows that on average temperature changes are more pronounced than moisture changes, especially in the period prior to LLC formation as well as after sunrise. Therefore, in the next step we investigate processes responsible for the observed temperature changes.

\subsection{Heat budget analysis}

Since the contribution of the temperature change is more dominant, i.e., cooling is the dominant process for LLC formation, we investigate in more detail the heat budget during 


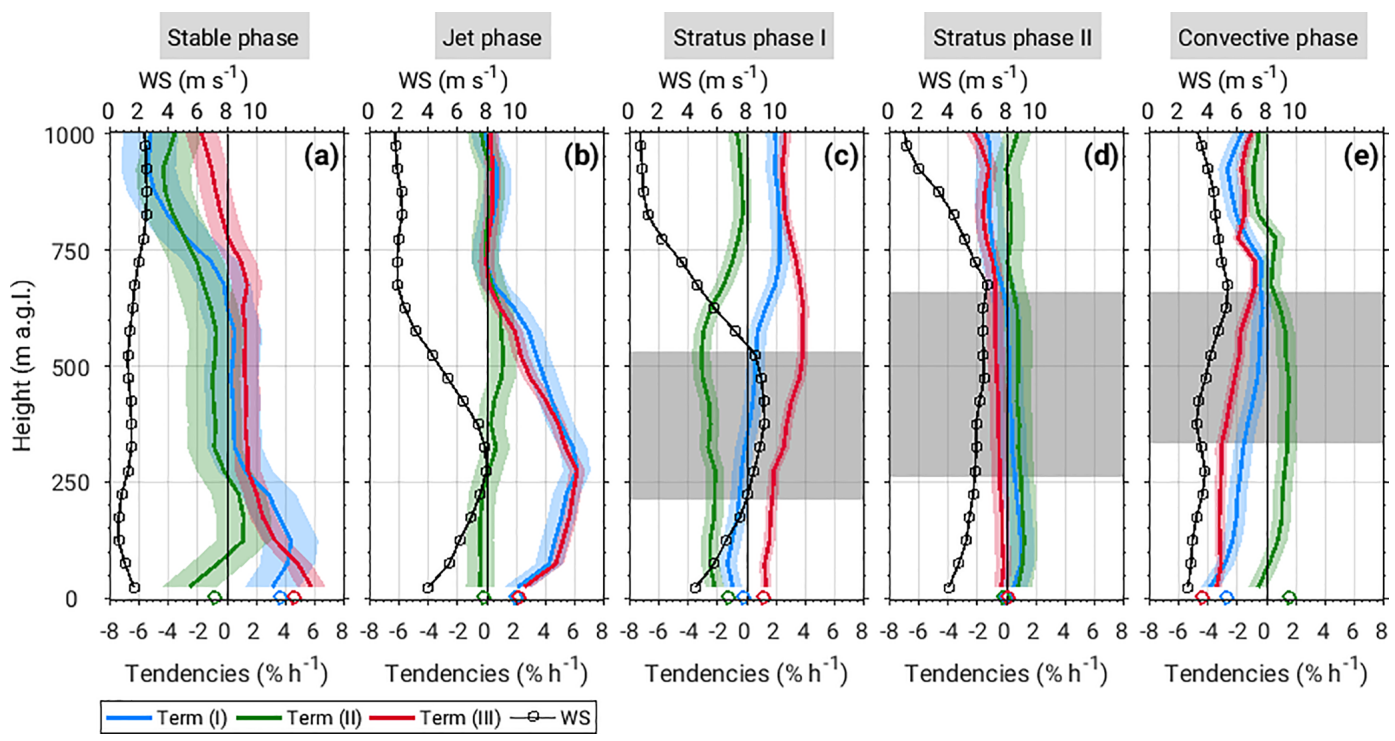

Figure 7. The observed RH tendency profiles (Term (I) in Eq. 1) obtained from radiosonde measurements for different phases during IOP 8 are shown in blue. The contributions from the specific humidity changes (Term (II) in Eq. 1) and temperature changes (Term (III) in Eq. 1) are shown in green and red, respectively. The shading indicates the range of uncertainty of each term determined based on the uncertainty propagation calculations. The colored circles show values of different terms of Eq. (1) obtained from near-surface measurements. The black circles denote the median horizontal wind speed (WS) profile for each phase. The mean cloud layer is indicated in gray shading.

this IOP. The conservation equation for the mean potential temperature $(\theta)$, with the molecular term neglected, is equal to (e.g., Garratt, 1992)

$$
\begin{gathered}
\underbrace{\frac{\partial \bar{\theta}}{\partial t}}_{(\mathrm{I})}=-\underbrace{\left(\bar{u} \frac{\partial \bar{\theta}}{\partial x}+\bar{v} \frac{\partial \bar{\theta}}{\partial y}+\bar{w} \frac{\partial \bar{\theta}}{\partial z}\right)}_{(\mathrm{II})} \\
+\underbrace{\frac{1}{\rho c_{\mathrm{p}}} \frac{\partial Q_{j}^{*}}{\partial z}}_{(\mathrm{III})}-\underbrace{\frac{L_{\mathrm{V}} E}{\rho c_{\mathrm{p}}}}_{(\mathrm{IV})}-\underbrace{\frac{\partial \overline{w^{\prime} \theta^{\prime}}}{\partial z}}_{(\mathrm{V})},
\end{gathered}
$$

where $c_{p}=1004 \mathrm{~J} \mathrm{~kg}^{-1} \mathrm{~K}^{-1}$ is the specific heat at constant air pressure, $\rho$ is density of the air, $Q_{j}^{*}$ is the net radiation flux, $E$ is the mass of water vapor per unit volume per unit time being created by a phase change from liquid or solid to gaseous and $\overline{w^{\prime} \theta^{\prime}}$ is the kinematic heat flux. We use radiosoundings in the same manner as in the previous section to calculate the potential temperature tendency (term I). The advection term (II) is considered here as a residual term since we can not calculate this term for each phase, but is estimated for a specific period in Sect. 4.3.1. The radiative flux divergence term (III) is determined using the radiative transfer (SBDART) model (Ricchiazzi et al., 1998). The latent heat release term (IV) is relevant in the case when clouds are present, and is determined from the LWP measurements (Fig. 3c), assuming that the liquid water content is linearly distributed over the cloud layer depth $(h)$, therefore, the phase change term equals $\frac{L_{\mathrm{v}} E}{\rho c_{\mathrm{p}}}=-\frac{L_{\mathrm{v}}}{c_{\mathrm{p}} \rho h} \frac{\partial(\mathrm{LWP})}{\partial t}$. Finally, the divergence of sensible heat flux $(V)$ is determined using the mean surface values of sensible heat flux $\left(H_{0}\right.$, Fig. $\left.5 d\right)$ for the respective phase and assuming linear decrease up to the top of the inversion layer (stable phase), to the NLLJ maximum (jet phase) or to the CBH during the nighttime conditions (stratus phase I and II). For the daytime conditions, we analyzed measurements of turbulent fluxes obtained by unmanned arial system (UAS) ALADINA (Altstädter et al., 2015; Bärfuss et al., 2018) in order to get the insight into their characteristics. Since the flight times of the UAS do not correspond to the time period of the convective phase, it is not possible to include them in the analysis directly. However, the analysis of 20 flights during the morning hours on 8 different days (not shown) indicates that it is reasonable to assume that sensible heat flux decreases linearly with height and equals $-0.2 H_{0}$ at the CTH (e.g., Stull, 1988; Wood, 2012).

Figure 8 shows the vertical profiles of heat budget terms for the five phases. The strong cooling of the layer below $300 \mathrm{~m}$ a.g.l. during the stable phase leads to the formation of the stably stratified nocturnal ABL. A large part of the observed cooling is due to the surface longwave radiative flux divergence with a maximum cooling rate of $-0.22 \mathrm{~K} \mathrm{~h}^{-1}$. When vertically averaged up to $275 \mathrm{~m}$ a.g.l., this term explains $29 \%$ of the observed temperature change, while contribution from sensible heat flux divergence is only $7 \%$. The residual term is found to be the largest, with $64 \%$ contribution to the observed temperature change during this period (Fig. 8a). The large residual term is most likely caused by the cold pool outflow, which resulted from the early evening local rainfall event which occurred approximately $15 \mathrm{~km}$ south 


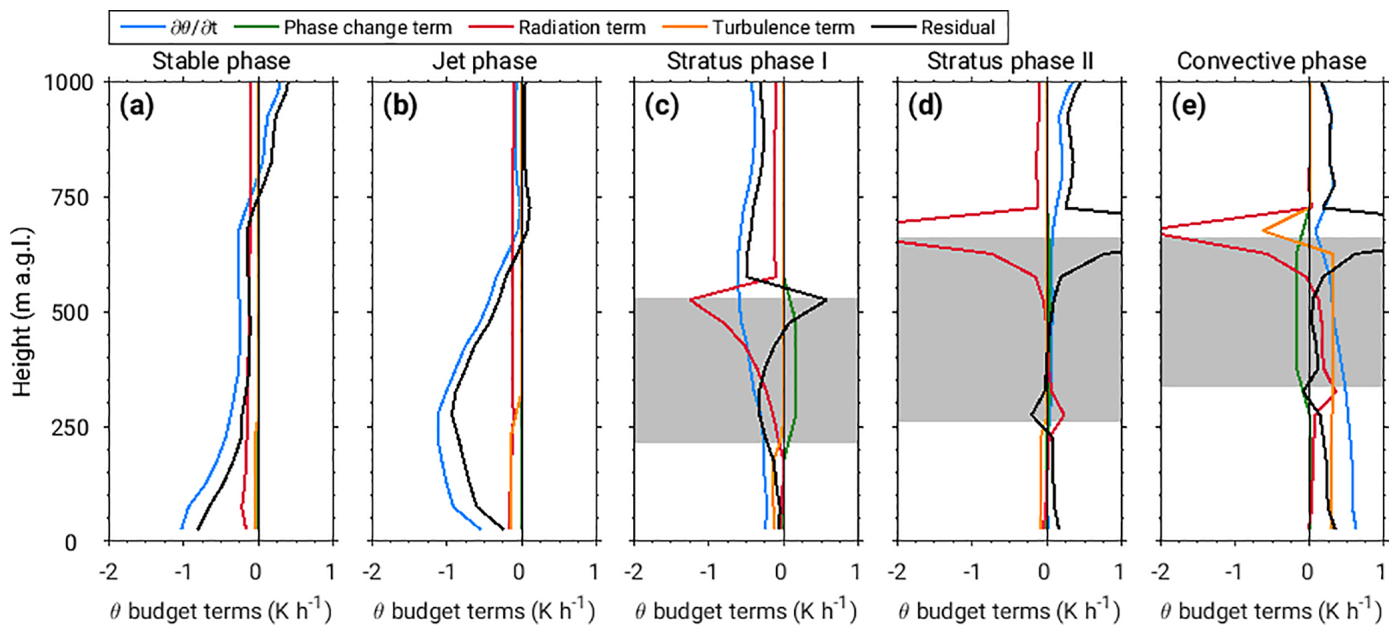

Figure 8. Vertical profiles of heat budget terms: potential temperature tendency (blue), phase change term (green), radiation flux divergence term (red), divergence of the sensible heat flux (orange), and residual term (black) shown for different phases during IOP 8 . The shaded gray area indicates the mean cloud layer.

of Savè and moved westward during its life cycle (between 19:00 and 21:00 UTC), as revealed by X-band radar data (not shown). These results are in general agreement with findings by Sun et al. (2003), who found that the strongest radiative flux divergence is observed in the early evening under weakwind and clear-sky conditions, which may contribute even up to $48 \%$ to the observed cooling in the lowest $48 \mathrm{~m}$ a.g.l.

After the arrival of the NLLJ, the layer of the strongest cooling deepens to $700 \mathrm{~m}$ a.g.l., with the maximum cooling rate of $-1.2 \mathrm{Kh}^{-1}$ at the height of the NLLJ maximum (Fig. 8b). Below the NLLJ maximum, the contribution of longwave radiation, which is still active during this cloudfree period, and of sensible heat flux divergence to the observed cooling, is approximately equal, i.e., $16 \%$. Based on $R i$ and radial velocity variance values (Fig. 5a), there is evidence of increased turbulent mixing below the NLLJ maximum, suggesting upward turbulent transport of cold air leading to cooling and an increase in RH in this layer (Fig. 6a, b). However, the contribution of longwave radiation and sensible heat flux divergence (due to turbulent mixing) to the observed cooling below the NLLJ maximum is substantially lower compared to the $68 \%$ contribution from the residual term. We assume that cooling due to the horizontal cold-air advection, associated with the onset of NLLJ, is most likely the reason for the strong decrease in temperature during the jet phase and is considered in more detail in the next subsection. These results are in general agreement with results obtained for 11 different IOPs by Adler et al. (2019); i.e., the average $22 \%$ radiative flux divergence contribution to the cooling during the stable and jet phases is in agreement with their results. Note that direct comparison of magnitudes is not advised since the methods applied differ slightly between the studies; therefore, some differences in the contributions from sensible heat flux divergence and horizontal advection to the observed cooling are obtained during these two phases.

During stratus phase I, the observed cooling below the $\mathrm{CBH}$ is mostly due to the strong vertical wind shear, which causes an increase in the sensible heat flux divergence and contributes $48 \%$ of the observed temperature change (Fig. 8c). The contribution of the radiative cooling is similar to the jet phase and is equal to $13 \%$. At the same time, the strong radiative cooling of $-1.3 \mathrm{~K} \mathrm{~h}^{-1}$ at the cloud top helps to maintain the cloud layer, which consequently evolves into dense stratus clouds by the end of this phase. The phase change term is positive within the cloud layer due to condensational heating. During stratus phase II, the atmospheric conditions below roughly $500 \mathrm{~m}$ a.g.l. are quasi-stationary; therefore, no substantial difference between the different terms is observed. The most pronounced feature is the strong radiative cooling of $-3 \mathrm{~K} \mathrm{~h}^{-1}$ at the cloud top (Fig. 8d). Normally, this strong radiative cooling at the cloud top leads to entrainment of air and increased turbulent mixing within the $\mathrm{ABL}$ (due to the density differences at the $\mathrm{CTH}$ ) and, subsequently, to the development of a strong capping inversion at the cloud top (e.g., Vilà-Guerau De Arellano et al., 2015). However, we do not observe the expected strong temperature inversion at the cloud top. Instead, in our case the radiative cooling is counter-balanced by the large-scale advection of warmer air in the layer up to $2 \mathrm{~km}$, leading to the observed weak heating at the cloud top. This horizontal warm-air advection is accompanied by a wind direction change (Fig. 6).

After sunrise, solar radiation heats the surface, causing positive sensible heat flux (Fig. 5d) and evolving CBL. Turbulent mixing due to buoyancy leads to upward transport of warm air from the surface and warming of the layer below the $\mathrm{CBH}$, which explains $52 \%$ of the warming of the CBL (Fig. 8e). However, due to the fact that sensible heat flux in- 
creases rapidly during convective phase (the mean and standard deviation are 93 and $45 \mathrm{~W} \mathrm{~m}^{-2}$, respectively), the estimation of the turbulence term is associated with high uncertainty. Within the clouds, the phase change term is negative due to the evaporative cooling.

\subsubsection{Horizontal temperature advection}

The large residual during the jet phase suggests that the horizontal cold-air advection related to the NLLJ arrival has an important contribution to the observed temperature change, which consequently led to the saturation and LLC formation. In conditions of undisturbed southwesterly monsoon flow, Adler et al. (2017) and Deetz et al. (2018b) observed a frequent occurrence of a stationary front, which formed along the Guinean coast in the afternoon and was located several tens of kilometers inland. This front was reflected in a strong gradient between the relatively cool air mass over the Gulf of Guinea and warm air over land. Northward propagation of the front started after 16:00 UTC, i.e., after decay of turbulence in the $\mathrm{CBL}$, and it reached the Savè region around 21:00 UTC. A similar stationary frontal structure was seen in the simulations by Grams et al. (2010) for the coast of Mauritania. They related its stationary during the day to a balance between horizontal advection within the onshore flow and turbulence in the CBL over the land. Based on previous numerical simulations, as well as the investigation of conditions along the coast (using radiosonde data) and at Savè, similar processes are expected to occur along the Guinean coast during the monsoon season. Specifically, we expect the horizontal cold advection to be related to the Gulf of Guinea maritime inflow which reaches Savè in the evening (Adler et al., 2019).

Figure 9a, b show the vertical profiles of wind speed and potential temperature from radiosoundings at the coast (Accra) and Savè. The conditions at the coast at 17:00 UTC are characterized by a strong monsoon flow of $8 \mathrm{~m} \mathrm{~s}^{-1}$, compared to low winds at Savè. On the other hand, the conditions at Savè are much warmer, with a well-mixed CBL. Generally, there are large differences in the conditions between the coast and Savè, as the coastal station seems to be in the cold maritime air mass, while a well-developed CBL dominates the conditions at Savè (Fig. 9a, b). At 23:00 UTC strong winds in Accra are still present, while the potential temperature decreased slightly. At the same time conditions at Savè have changed substantially: the wind profile is now characterized by a pronounced NLLJ up to $8 \mathrm{~m} \mathrm{~s}^{-1}$, which is the same as at the coast, and potential temperature decreased considerably to about $299 \mathrm{~K}$ in the layer below $600 \mathrm{~m}$ a.g.l.; i.e., it has nearly the same value as at the coast during the daytime. Based on these considerations we conclude that the front of the Gulf of Guinea maritime inflow with maritime air mass already passed Savè at this time. In the layer above $750 \mathrm{~m}$ a.g.l. conditions at Savè do not change considerably during this period.
The estimation of the horizontal temperature advection is based on several assumptions, which are described in detail in Adler et al. (2019). These include (i) the assumption of homogeneous temperature distribution along the coast, (ii) neglecting the zonal wind component, (iii) gradual (linear) increase in temperature in the south-north direction within the maritime inflow air mass at a certain distance from the coast (due to the position of the maritime air mass front), and (iv) constant temperature in the continental ABL north of the front. Recent modeling studies (Adler et al., 2017; Deetz et al., 2018b) indicate that the maximum inland penetration of the maritime air mass front in the afternoon hours is between 50 and $125 \mathrm{~km}$ inland from the coast. Therefore, we estimate the contribution of horizontal advection to cooling at Savè during the stable and jet phases, using radiosonde measurements at the coast (Accra) and Savè (Fig. 9c). The meridional temperature difference for four different front locations $(50,75,100$, and $125 \mathrm{~km}$ inland) is determined at 17:00 UTC, while the mean (meridional $v$ ) wind is the average of measurements at 17:00 UTC in Accra and 23:00 UTC at Savè. The horizontal advection $\left(-v \Delta \theta \Delta y^{-1}\right)$ estimate indicates a maximum cooling rate of $-2.7 \mathrm{~K}(6 \mathrm{~h})^{-1}$ at the height of the NLLJ maximum. When we compare estimated horizontal advection to the potential temperature tendency at Savè for the time period 17:00 to 23:00 UTC, above the NLLJ maximum there is an almost perfect fit (Fig. 9c), indicating that cooling in this layer can be explained by horizontal advection. Below the NLLJ maximum, the contribution of horizontal advection is $55 \%$ to the observed cooling, which explains the large part of the heat budget residual term during the jet phase and is in good agreement with the estimated average contribution from horizontal advection to cooling during the stable and jet phases for the whole DACCIWA campaign (Adler et al., 2019). Since for IOP 8 radiosonde data are available every $1.5 \mathrm{~h}$, we could determine the contribution of horizontal advection to the heat budget for the stable and jet phases separately. Related to the jet phase, which is characterized by the largest temperature change and the arrival of the NLLJ, the contribution by cold-air advection accounts for almost $70 \%$, while its contribution accounts for $55 \%$ when relating it to the period from 17:00 to 23:00 UTC.

\section{Discussion}

Satellite images reveal that during this particular IOP, first LLC form east of the Atakora Mountains in Togo and upstream of Oshogbo Hills in Nigeria. The location of LLC confined to mountainous regions suggests that orographically induced lifting is one important process relevant for their formation as found in modeling studies of Schuster et al. (2013) and Adler et al. (2017). In subsequent hours, the clouds in the region of the Atakora Mountains extend towards the northeast, i.e., upstream of Savè. The evolution of LLC at Savè suggests that they are not advected from southwest, where 

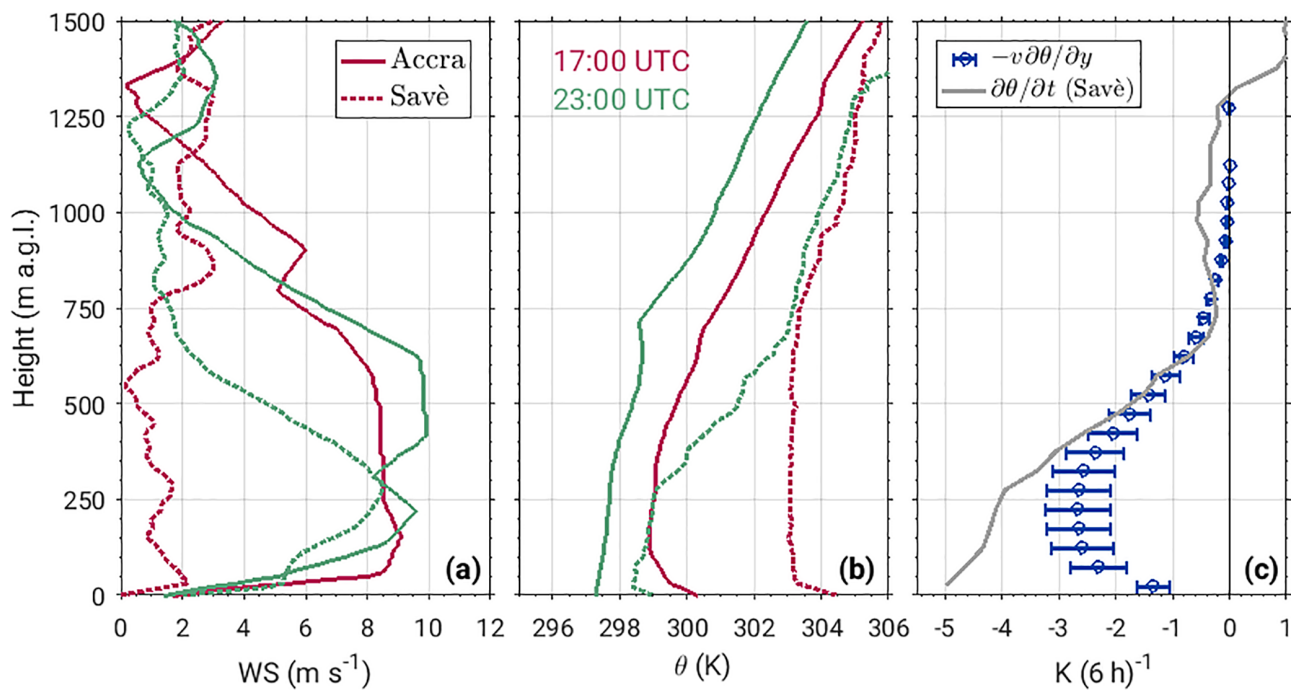

Figure 9. Comparison of vertical profiles of horizontal wind speed (a) and potential temperature (b) in Accra (solid line) and Savè (dashed line) at 17:00 (red) and 23:00 UTC (green). (c) The mean horizontal advection estimated between the coast and Savè for different front locations $(50,75,100$, and $125 \mathrm{~km}$ from the coast) during the $6 \mathrm{~h}$ period (17:00-23:00 UTC) using radiosonde measurements in Accra and Savè (blue), while the error bars show 1 standard deviation. The potential temperature change observed at Savè during this period is shown in gray.

they form first, but they most likely form due to favorable atmospheric conditions, such as horizontal cold-air advection, longwave radiative cooling, and sensible heat flux divergence. During the DACCIWA campaign, different regions of LLC formation were recorded; i.e., in some cases the first clouds formed over higher terrain, while for other nights they seem to be independent of terrain features, and these are presented in more detail in Adler et al. (2019).

The heat budget analysis suggests that the most relevant process for the LLC formation is cooling due to horizontal cold-air advection, which is associated with the arrival of maritime inflow indicated by cold air mass and southwesterly NLLJ. Although there are large uncertainties related to the estimation of the horizontal temperature advection (Adler et al., 2019), we are certain that this process contributes the most to the LLC formation. Our results suggest that the contribution from horizontal cold advection can be up to $68 \%$ during the jet phase when cooling is strongest. The difference in the horizontal advection estimation between this study and Adler et al. (2019) comes from the limitations in the temporal resolution of radiosondes; i.e., Adler et al. (2019) can not perform the heat budget analysis in a consistent manner since during some IOPs radiosondes between 17:00 and 21:00 UTC are not available. For this reason they need to include periods when horizontal advection is not active, which results in a lower contribution of $55 \%$ during the longer time period (stable and jet phases). The horizontal cold-air advection was also found to be an important process in numerical simulation (Schuster et al., 2013; Adler et al., 2017). Our results highlight the importance of having a dense network of measurements, as well as resolving the atmospheric condi- tions at high temporal and spatial resolution in order to adequately quantify all processes relevant for LLC. For example, Schuster et al. (2013) quantified the cooling rate due to horizontal cold-air advection to be $-5 \mathrm{~K}(12 \mathrm{~h})^{-1}$. This rate is similar to the observed potential temperature change between 17:00 and 23:00 UTC at Savè (Fig. 9c). However, as seen in this study, the cooling due to the cold-air advection at Savè occurs during a much shorter period (20:00 to 00:00 UTC, Fig. 4), suggesting that our rate of $-1 \mathrm{Kh}^{-1}$ during the jet phase gives a more reliable estimation of the horizontal advection magnitude. This cold air mass behind the maritime inflow is also drier compared to the continental air mass, thus giving an observational confirmation of findings from numerical simulations (Schuster et al., 2013; Adler et al., 2017).

On the other hand, previous observational studies identified upward mixing of moisture, due to the increased vertical wind shear related to the NLLJ, as the main process for the cloud formation (Schrage and Fink, 2012). Although the vertical mixing of cold air from the surface layer aloft is found to have a non-negligible contribution to the overall cooling, which leads to the saturation and cloud formation, this is not the main process (cf. Adler et al., 2019).

In the simulations of Schuster et al. (2013) and Adler et al. (2017), a shift of the NLLJ maximum towards the cloud top was found, which is now verified by the observations. This upward shift of the NLLJ maximum is found to be due to the change in the stratification within the cloud layer, compared to the cloud-free period (jet-to-stratus phase I change). The wind-shear-induced mixing below the NLLJ maximum (at the height of $275 \mathrm{~m}$ a.g.l., Fig. 5a) reduces the gradient of the potential temperature, resulting in a less stably stratified 
layer below the NLLJ maximum than above. With the cloud formation, vertical gradients in wind speed and temperature decrease further, causing the thickening of the mixed layer and consequently the shift of the inversion layer upwards. Adler et al. (2017) found the shift in stratification within the clouds to be caused by the enhanced TKE, condensational heating, radiative cooling at the cloud top, and upward motion in the stable ABL. All of the processes are observed in our study as well, except for the latter, since due to the uncertain measurements of vertical wind velocity by Doppler lidars we can not estimate the contribution of upward motion.

\section{Summary and conclusions}

The data collected during a comprehensive DACCIWA ground-based field campaign at the supersite in Savè (Benin) on 7-8 July 2016 are analyzed in order to investigate the diurnal cycle of LLC and related atmospheric processes. This particular time period is chosen since the conditions during this case study reflect typical conditions and features related to undisturbed southwesterly monsoon flow. These typical features include the onset of NLLJ and the formation of LLC. The associated dynamic and thermodynamic conditions allow the identification of five different nocturnal phases. These include the stable phase indicating the period after the sunset and before the onset of the NLLJ, when the wind speed in the ABL is low and increasing static stability causes the decoupling of the mixed layer from the stable ABL. The jet phase starts with the onset of NLLJ related to the arrival of Gulf of Guinea maritime inflow. The formation of LLC marks the beginning of the stratus phase, which is divided in stratus phase I, since the inhomogeneous cloud cover and nonstationary atmospheric conditions are observed, and stratus phase II, which corresponds to the period with a persistent stratus deck and quasi-stationary atmospheric conditions. The convective phase starts approximately $1 \mathrm{~h}$ after the sunrise and is associated with growing CBL and lifting of the cloud base.

Shortly after the sunset, the stably stratified nocturnal boundary layer developed due to the contributions of longwave radiative cooling of the ground $(29 \%)$, sensible heat flux divergence (7\%), as well as some local effects due to cold pool outflow from early evening convection, causing the decoupling of the mixed layer from the stable surface layer (stable phase). Within the stable ABL, RH increased with a maximum rate of about $4 \% \mathrm{~h}^{-1}$ mostly due to strong cooling in this layer. The jet phase is characterized by the southwesterly NLLJ, which causes an increase in wind speed of up to $8 \mathrm{~m} \mathrm{~s}^{-1}$ and the NLLJ maximum height at about $275 \mathrm{~m}$ a.g.l. The strong wind shear below the NLLJ causes increased vertical turbulent mixing and consequently the erosion of the surface inversion, leading to the coupling of the residual and surface layer. The effect of horizontal cold-air advection, re- lated to the Gulf of Guinea maritime inflow, which brings the cold maritime air mass and a prominent NLLJ wind profile, is found to have the dominant role in the observed strong cooling during the jet phase. The residual term of the heat budget is considered to correspond to the horizontal temperature advection term, and we find that it can contribute up to $68 \%$ to the observed temperature change below the NLLJ maximum during the jet phase. The contribution from both radiative cooling and sensible heat flux divergence is $16 \%$, respectively. The cooling at a rate of $-1.2 \mathrm{~K} \mathrm{~h}^{-1}$ persists for approximately $3 \mathrm{~h}$, causing the continuous increase in $\mathrm{RH}$ at a rate of $6 \% \mathrm{~h}^{-1}$, until finally the saturation is reached and LLC form at the height corresponding to the NLLJ maximum height. No significant contribution from the moistening is found during this phase. The nonstationary conditions during stratus phase I are observed due to competing influences of processes leading to cooling, namely turbulent mixing and cold-air advection, and a dry air advection, related to the drier maritime air mass behind the maritime inflow front, thus leading to inhomogeneous and thin cloud cover. A combining effect of the vertical wind shear below and above the NLLJ maximum and the presence of LLC leads to the change in stratification, causing lower static stability in the sub-cloud layer and higher at the cloud top, which in turn results in an upward shift of the NLLJ maximum (from 275 to roughly 400 m a.g.l.). This shift of the NLLJ maximum towards the layer of maximum static stability continues in stratus phase II as quasi-stationary conditions are established. Turbulent mixing is an important factor leading to the cooling below the cloud base, while strong radiative cooling at the cloud top with a rate of approximately $-2 \mathrm{Kh}^{-1}$ helps to maintain thick stratus. In the morning, the $52 \%$ contribution from sensible heat flux divergence to the observed heating below the $\mathrm{CBH}$ is the largest and, consequently, leads to continuous warming of the $\mathrm{CBL}$, lifting of the $\mathrm{CBH}$, and dissolution of LLC.

Overall, this study presents the first detailed observational analysis of the complete diurnal cycle of LLC and processes leading to their formation, maintenance, and dissolution over southern West Africa. This comprehensive data set enabled the verification of the previous numerical results, as well as revealed some new findings enabling better understanding of processes related to the West African monsoon. This mostly concerns the role of the maritime inflow and associated horizontal advection of cold but also drier air for the LLC formation. Furthermore, this detailed analysis of the diurnal cycle of LLC and related conditions and processes is expected to substantially contribute to the development of the conceptual model of the LLC life cycle.

Data availability. The DACCIWA data from the Savè supersite are available on the SEDOO database (http://baobab.sedoo. fr/DACCIWA/) (Derrien et al., 2016; Handwerker et al., 2016; 
Kohler et al., 2016; Wieser et al., 2016) for scientists interested in boundary-layer studies in southern West Africa.

Author contributions. KB wrote the paper with contributions from all co-authors. KB carried out the data analysis and prepared most of the figures. HA processed the satellite data. BA, NK, CD, FL, ML, and XPB contributed to the data analysis, interpretation of results, and conducted the ground-based measurements.

Competing interests. The authors declare that they have no conflict of interest.

Special issue statement. This article is part of the special issue "Results of the project "Dynamics-aerosol-chemistry-cloud interactions in West Africa" (DACCIWA) (ACP/AMT inter-journal SI)". It is not associated with a conference.

Acknowledgements. The DACCIWA project has received funding from the European Union Seventh Framework Programme (FP7/2007-2013) under grant agreement no. 603502. We thank two anonymous reviewers for their valuable comments and suggestions. We thank the staff of KIT (Karlsruhe Institute of Technology) and UPS (University of Toulouse) for helping to install and run the equipment, as well as the staff of the Institute of Agricultural Research of Benin, Cotonou (INRAB) in Savè, for allowing us to use their grounds for the experiment. We thank Andreas Fink and his group for performing the radiosoundings at Accra and Christine Chiu for providing the SBDART code which uses Mie phase function calculations.

The article processing charges for this open-access publication were covered by a Research

Centre of the Helmholtz Association.

Edited by: Susan van den Heever

Reviewed by: two anonymous referees

\section{References}

Adler, B., Kalthoff, N., and Gantner, L.: Nocturnal low-level clouds over southern West Africa analysed using highresolution simulations, Atmos. Chem. Phys., 17, 899-910, https://doi.org/10.5194/acp-17-899-2017, 2017.

Adler, B., Babić, K., Kalthoff, N., Lohou, F., Lothon, M., Dione, C., Pedruzo-Bagazgoitia, X., and Andersen, H.: Nocturnal low-level clouds in the atmospheric boundary layer over southern West Africa: an observation-based analysis of conditions and processes, Atmos. Chem. Phys., 19, 663-681, https://doi.org/10.5194/acp-19-663-2019, 2019.

Altstädter, B., Platis, A., Wehner, B., Scholtz, A., Wildmann, N., Hermann, M., Käthner, R., Baars, H., Bange, J., and Lampert, A.: ALADINA - an unmanned research aircraft for observing vertical and horizontal distributions of ultrafine particles within the atmospheric boundary layer, Atmos. Meas. Tech., 8, 16271639, https://doi.org/10.5194/amt-8-1627-2015, 2015.

Bärfuss, K., Pätzold, F., Altstädter, B., Kathe, E., Nowak, S., Bretschneider, L., Bestmann, U., and Lampert, A.: New setup of the UAS ALADINA for measuring boundary layer properties, atmospheric particles and solar radiation, Atmosphere, 9, 28, https://doi.org/10.3390/atmos9010028, 2018.

Bauer-Pfundstein, M. R. and Goersdorf, U.: Target separation and classification using cloud radar Doppler-spectra, in: Proceedings of the 33rd Intern. Conf. on Radar Meteorology, Cairns, Australia, vol. 11.B2, 1-8, https://ams.confex.com/ams/33Radar/ techprogram/paper_123456.htm (last access: 29 January 2019), 2007.

Bessardon, G., Brooks, B., Abiye, O., Adler, B., Ajao, A., Ajileye, O., Altstädter, B., Amekudzi, L. K., Aryee, J. N. A., Atiah, W. A., Ayoola, M., Babić, K., Bärfuss, K., Bezombes, Y., Bret, G., Brilouet, P.-E., Cayle-Aethelhard, F., Danuor, S., Delon, C., Derrien, S., Dione, C., Durand, P., Fosu-Amankwah, K., Gabella, O., Groves, J., Handwerker, J., Kalthoff, N., Kohler, M., Kunka, N., Jambert, C., Jegede, G., Lampert, A., Leclercq, J., Lohou, F., Lothon, M., Medina, P., Pätzold, F., Pedruzo Bagazgoitia, X., Reinares, I., Sharpe, S., Smith, V., Sunmonu, L. A., Tan, N., and Wieser, A.: A dataset of the 2016 monsoon season meteorology in southern West Africa - an overview from the DACCIWA campaign, Sci. Data, in review, 2019.

Bonin, T. A., Choukulkar, A., Brewer, W. A., Sandberg, S. P., Weickmann, A. M., Pichugina, Y. L., Banta, R. M., Oncley, S. P., and Wolfe, D. E.: Evaluation of turbulence measurement techniques from a single Doppler lidar, Atmos. Meas. Tech., 10, 3021, https://doi.org/10.5194/amt-10-3021-2017, 2017.

Browning, K. A. and Wexler, R.: The determination of kinematic properties of a wind field using Doppler radar, J. Appl. Meteorol., 7, 105-113, https://doi.org/10.1175/15200450(1968)007<0105:TDOKPO>2.0.CO;2, 1968.

Cermak, J. and Bendix, J.: Dynamical nighttime fog/low stratus detection based on Meteosat SEVIRI data: A feasibility study, Pure Appl. Geophys., 164, 1179-1192, https://doi.org/10.1007/s00024-007-0213-8, 2007.

Cermak, J. and Bendix, J.: A novel approach to fog/low stratus detection using Meteosat 8 data, Atmos. Res., 87, 279-292, https://doi.org/10.1016/j.atmosres.2007.11.009, 2008.

Deetz, K., Vogel, H., Haslett, S., Knippertz, P., Coe, H., and Vogel, B.: Aerosol liquid water content in the moist southern West African monsoon layer and its radiative impact, Atmos. Chem. Phys., 18, 14271-14295, https://doi.org/10.5194/acp-18-142712018, 2018a.

Deetz, K., Vogel, H., Knippertz, P., Adler, B., Taylor, J., Coe, H., Bower, K., Haslett, S., Flynn, M., Dorsey, J., Crawford, I., Kottmeier, C., and Vogel, B.: Numerical simulations of aerosol radiative effects and their impact on clouds and atmospheric dynamics over southern West Africa, Atmos. Chem. Phys., 18, 9767-9788, https://doi.org/10.5194/acp-18-9767-2018, $2018 \mathrm{~b}$.

Derrien, S., Bezombes, Y., Bret, B., Gabella, O., Jarnot, C., Medina, P., Piques, E., Delon, C., Dione, C., Campistron, B., Durand, P., Jambert, C., Lohou, F., Lothon, M., Pacifico, F., and Meyerfeld, Y.: DACCIWA field campaign, Savè super-site, UPS instrumentation, SEDOO OMP, https://doi.org/10.6096/dacciwa.1618, 2016. 
Dione, C., Lohou, F., Lothon, M., Adler, B., Babić, K., Kalthoff, N., Pedruzo-Bagazgoitia, X., Bezombes, Y., and Gabella, O.: Low Level Cloud and Dynamical Features within the Southern West African Monsoon, Atmos. Chem. Phys. Discuss., https://doi.org/10.5194/acp-2018-1149, in review, 2018.

Eyre, J. R., Brownscombe, J. L., and Allam, R. J.: Detection of fog at night using Advanced Very High Resolution Radiometer (AVHRR) imagery, Meteorol. Mag., 266-271, 1984.

Flamant, C., Knippertz, P., Fink, A. H., Akpo, A., Brooks, B., Chiu, C. J., Coe, H., Danuor, S., Evans, M., Jegede, O., Kalthoff, N., Konarè, A., Liousse, C., Lohou, F., Mari, C., Schlager, H., Schwarzenboeck, A., Adler, B., Amekudzi, L., Aryee, J., Ayoola, M., Batenburg, A. M., Bessardon, G., Borrmann, S., Brito, J., Bower, K., Burnet, F., Catoire, V., Colomb, A., Denjean, C., Fosu-Amankwah, K., Hill, P. G., Lee, J., Lothon, M., Maranan, M., Marsham, J., Meynadier, R., Ngamini, J.-B., Rosenberg, P., Sauer, D., Smith, V., Stratmann, G., Taylor, J. W., Voigt, C., and Yoboué, V.: The Dynamics-Aerosol-ChemistryCloud Interactions in West Africa field campaign: Overview and research highlights, B. Am. Meteorol. Soc., 99, 83-104, https://doi.org/10.1175/BAMS-D-16-0256.1, 2018.

Garratt, J.: The Atmospheric Boundary Layer, Cambridge University, Cambridge, 316 pp., 1992.

Grams, C. M., Jones, S. C., Marsham, J. H., Parker, D. J., Haywood, J. M., and Heuveline, V.: The Atlantic inflow to the Saharan heat low: observations and modelling, Q. J. Roy. Meteor. Soc., 136, 125-140, https://doi.org/10.1002/qj.429, 2010.

Handwerker, J., Scheer, S., and Gamer, T.: DACCIWA field campaign, Savè super-site, Cloud and precipitation, SEDOO OMP, https://doi.org/10.6096/dacciwa.1686, 2016.

Hannak, L., Knippertz, P., Fink, A. H., Kniffka, A., and Pante, G.: Why do global climate models struggle to represent low-level clouds in the West African summer monsoon?, J. Clim., 30, 1665-1687, https://doi.org/10.1175/JCLI-D-16-0451.1, 2017.

Haslett, S. L., Taylor, J. W., Deetz, K., Vogel, B., Babić, K., Kalthoff, N., Wieser, A., Dione, C., Lohou, F., Brito, J., Dupuy, R., Schwarzenboeck, A., and Coe, H.: The radiative impact of out-of-cloud aerosol hygroscopic growth during the summer monsoon in southernWest Africa, Atmos. Chem. Phys. Discuss., https://doi.org/10.5194/acp-2018-805, in review, 2018.

Hill, P. G., Allan, R. P., Chiu, J. C., Bodas-Salcedo, A., and Knippertz, P.: Quantifying the contribution of different cloud types to the radiation budget in southern West Africa, J. Clim., 31, 52735291, https://doi.org/10.1175/JCLI-D-17-0586.1, 2018.

Hunt, G. E.: Radiative properties of terrestrial clouds at visible and infrared thermal window wavelengths, Q. J. Roy. Meteor. Soc., 99, 349-369, https://doi.org/10.1002/qj.49709942013, 1973.

Kalthoff, N., Lohou, F., Brooks, B., Jegede, G., Adler, B., Babić, K., Dione, C., Ajao, A., Amekudzi, L. K., Aryee, J. N. A., Ayoola, M., Bessardon, G., Danuor, S. K., Handwerker, J., Kohler, M., Lothon, M., Pedruzo-Bagazgoitia, X., Smith, V., Sunmonu, L., Wieser, A., Fink, A. H., and Knippertz, P.: An overview of the diurnal cycle of the atmospheric boundary layer during the West African monsoon season: results from the 2016 observational campaign, Atmos. Chem. Phys., 18, 2913-2928, https://doi.org/10.5194/acp-18-2913-2018, 2018.

Knippertz, P., Fink, A. H., Schuster, R., Trentmann, J., and Schrage, J.: Ultra-low clouds over the southern West
African monsoon region, Geophys. Res. Lett., 38, L21808, https://doi.org/10.1029/2011GL049278, 2011.

Knippertz, P., Coe, H., Chiu, J. C., Evans, M. J., Fink, A. H., Kalthoff, N., Liousse, C., Mari, C., Allan, R. P., Brooks, B., Danour, S., Flamant, C., Jegede, O. O., Lohou, F., and Marsham, J. H.: The DACCIWA Project: Dynamics-AerosolChemistry-Cloud Interactions in West Africa, B. Am. Meteorol. Soc., 96, 1451-1460, https://doi.org/10.1175/BAMS-D-14$00108.1,2015$.

Knippertz, P., Fink, A. H., Deroubaix, A., Morris, E., Tocquer, F., Evans, M. J., Flamant, C., Gaetani, M., Lavaysse, C., Mari, C., Marsham, J. H., Meynadier, R., Affo-Dogo, A., Bahaga, T., Brosse, F., Deetz, K., Guebsi, R., Latifou, I., Maranan, M., Rosenberg, P. D., and Schlueter, A.: A meteorological and chemical overview of the DACCIWA field campaign in West Africa in June-July 2016, Atmos. Chem. Phys., 17, 10893-10918, https://doi.org/10.5194/acp-17-10893-2017, 2017.

Kohler, M., Kalthoff, N., Seringer, J., and Kraut, S.: DACCIWA field campaign, Savè super-site, Surface measurements, SEDOO OMP, https://doi.org/10.6096/dacciwa.1690, 2016.

Löhnert, U. and Crewell, S.: Accuracy of cloud liquid water path from ground-based microwave radiometry. 1: Dependency on cloud model statistics, Radio Sci., 38, 8041, https://doi.org/10.1029/2002RS002654, 2003.

Löhnert, U., Turner, D., and Crewell, S.: Ground-based temperature and humidity profiling using spectral infrared and microwave observations. Part I: Simulated retrieval performance in clear-sky conditions, J. Appl. Meteorol. Clim., 48, 1017-1032, https://doi.org/10.1175/2008JAMC2060.1, 2009.

Lothon, M., Saï, F., Lohou, F., and Campistron, B.: Observation of the diurnal cycle in the low trophosphere of West Africa, Mon. Weather Rev., 136, 3477-3500, https://doi.org/10.1175/2008MWR2427.1, 2008.

Mauder, M., Cuntz, M., Drüe, C., Graf, A., Rebmann, C., Schmid, H. P., Schmidt, M., and Steinbrecher, R.: A strategy for quality and uncertainty assessment of long-term eddycovariance measurements, Agr. Forest Meteorol., 169, 122-135, https://doi.org/10.1016/j.agrformet.2012.09.006, 2013.

Ricchiazzi, P., Yang, S., Gautier, C., and Sowle, D.: SBDART: A research and teaching software tool for planeparallel radiative transfer in the Earth's atmosphere, B. Am. Meteorol. Soc., 79, 2101-2114, https://doi.org/10.1175/15200477(1998)079<2101:SARATS>2.0.CO;2, 1998.

Schmetz, J., Pili, P., Tjemkes, S., Just, D., Kerkmann, J., Rota, S., and Ratier, A.: An introduction to Meteosat Second generation (MSG), B. Am. Meteorol. Soc., 83, 977-992, https://doi.org/10.1175/15200477(2002)083<0977:AITMSG>2.3.CO;2, 2002.

Schrage, J. M. and Fink, A. H.: Nocturnal continental low-level stratus over tropical West Africa: Observations and possible mechanisms controlling its onset, Mon. Weather Rev., 140, 1794-1809, https://doi.org/10.1175/MWR-D-11-00172.1, 2012.

Schuster, R., Fink, A. H., and Knippertz, P.: Formation and maintenance of nocturnal low-level stratus over the southern West African monsoon region during AMMA 2006, J. Atmos. Sci., 70, 2337-2355, https://doi.org/10.1175/JAS-D-12-0241.1, 2013.

Stull, R. B.: An Introduction to Boundary-Layer Meteorology, Kluwer Academic Dordrecht, 680 pp., 1988. 
Sun, J., Burns, S. P., Delany, A. C., Oncley, S. P., Horst, T. W., and Lenschow, D. H.: Heat balance in the nocturnal boundary layer during CASES-99, J. Appl. Meteorol., 42, 1649-1666, https://doi.org/10.1175/15200450(2003)042<1649:HBITNB>2.0.CO;2, 2003.

Sun, J., Lenschow, D. H., LeMone, M. A., and Mahrt, L.: The role of large-coherent-eddy transport in the atmospheric surface layer based on CASES-99 observations, Bound.-Lay. Meteorol., 160, 83-111, https://doi.org/10.1007/s10546-016-0134-0, 2016.

Taylor, J. W., Haslett, S. L., Bower, K., Flynn, M., Crawford, I., Dorsey, J., Choularton, T., Connolly, P. J., Hahn, V., Voigt, C., Sauer, D., Dupuy, R., Brito, J., Schwarzenboeck, A., Bourriane, T., Denjean, C., Rosenberg, P., Flamant, C., Lee, J. D., Vaughan, A. R., Hill, P. G., Brooks, B., Catoire, V., Knippertz, P., and Coe, H.: Aerosol influences on low-level clouds in the West African monsoon, Atmos. Chem. Phys. Discuss., https://doi.org/10.5194/acp-2019-40, in review, 2019.

van der Linden, R., Fink, A. H., and Redl, R.: Satellite-based climatology of low-level continental clouds in southern West Africa during the summer monsoon season, J. Geophys. Res., 120, 1186-1201, https://doi.org/10.1002/2014JD022614, 2015.
Vilà-Guerau De Arellano, J., van Heerwaarden, C., van Stratum, B., and van den Dries, C.: Atmospheric Boundary Layer, Integrating Air Chemistry and Land Interactions, Cambridge University Press, New York, https://doi.org/10.1017/CBO9781316117422, 2015.

Wieser, A., Adler, B., and Deny, B.: DACCIWA field campaign, Savè super-site, Thermodynamic data sets, SEDOO OMP, https://doi.org/10.6096/dacciwa.1659, 2016.

Wood, R.: Stratocumulus clouds, Mon. Weather Rev., 140, 2373 2423, https://doi.org/10.1175/MWR-D-11-00121.1, 2012.

Zhu, P., Albrecht, B., and Gottschalck, J.: Formation and development of nocturnal boundary layer clouds over the southern Great Plains, J. Atmos. Sci., 58, 1409-1426, https://doi.org/10.1175/15200469(2001)058<1409:FADONB >2.0.CO;2, 2001. 